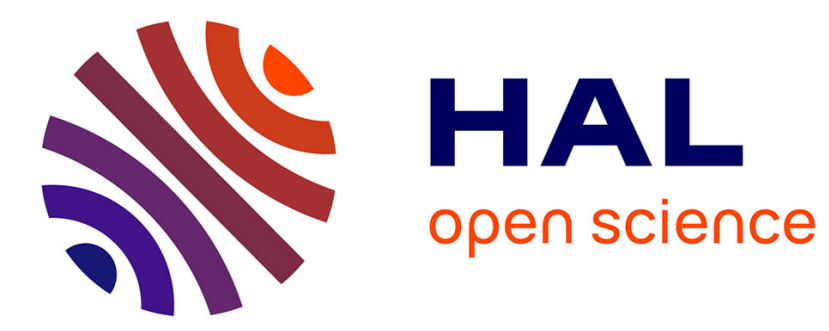

\title{
Toward Physically-Based Explosive Modeling: Meso-Scale Investigations
}

Hervé Trumel, Philippe Lambert, Guillaume Vivier, Yves Sadou

\section{To cite this version:}

Hervé Trumel, Philippe Lambert, Guillaume Vivier, Yves Sadou. Toward Physically-Based Explosive Modeling: Meso-Scale Investigations. Materials under Extreme Loadings, John Wiley \& Sons, pp.179207, 2013, 10.1002/9781118622612.ch9 . hal-03413719

\section{HAL Id: hal-03413719 https://hal.science/hal-03413719}

Submitted on 9 Nov 2021

HAL is a multi-disciplinary open access archive for the deposit and dissemination of scientific research documents, whether they are published or not. The documents may come from teaching and research institutions in France or abroad, or from public or private research centers.
L'archive ouverte pluridisciplinaire HAL, est destinée au dépôt et à la diffusion de documents scientifiques de niveau recherche, publiés ou non, émanant des établissements d'enseignement et de recherche français ou étrangers, des laboratoires publics ou privés.

\section{다)(1) $(5$}

Distributed under a Creative Commons Attribution - NonCommercial| 4.0 International 


\section{Toward Physically-Based Explosive Modeling: Meso-Scale Investigations}

Hervé Trumel, Philippe LAmBert, Guillaume VIVIER and Yves SAdOU

\subsection{Introduction}

Out of their "normal" shock-to-detonation loading range, explosives can be considered as ordinary materials and studied and modeled from the mechanical and material science standpoints. Some of them do exhibit a dynamic behavior quite close to that of geomaterials. This will be illustrated here for the engineering problem of low velocity impacts, crucial with regard to safety issues and yet poorly understood.

It is well known that the initiation of impact-induced explosions involves "hot spots", that is, local temperature peaks resulting from heterogenous dissipative mechanisms [BOW 52]. Understanding such phenomena compels us to recognize that the macroscopic scale is not relevant, and that mechanical processes take place prior to reaction. It is thus required to study micromechanical and hot spot processes as well, using appropriate experimental tools. This approach was already used a few years ago with some success on a TATB-based explosive [DEM 95, LEG 04] in relation to the shock-to-detonation process.

Explosives and solid propellants constitute a wide class of energetic materials. Most of them consist in energetic crystals bonded with polymeric binders. In the general case, the filler volume fraction is larger than $70 \%$ and the grain size distribution must be broad. If strain compliance is sought, the amount of binder 
should not be lower than, say, $20 \%$, and adhesive additives are employed, so as to prevent strain-induced damage. This is the case of propellant-like materials, generally manufactured by vacuum casting and low temperature curing. If, on the other hand, chemical energy is primarily sought, the amount of binder may be as low as $5 \%$. In this case, the energetic crystals are coated by the binder, and the resulting molding powder must be processed by high pressure isostatic pressing.

In both cases, the resulting microstructure is highly heterogenous, and these materials display a mechanical behavior somewhat intermediate between rock-like and polymer-like [TRU 01a, GRA 06, GRA 09]. Strong pressure and strain-rate sensitivity are in any case of their main mechanical characteristics. Macroscopic phenomenological modelling reveals difficult to build and generally displays limited predictive capabilities [TRU 01b]. It is thus desirable to build physically-based models [NAD 06, VIV 07, VIV 09], for which a deep knowledge of the small scale deformation and reaction physics of these materials is required.

It has been known for long that energetic material ignition is a thermally activated process. Thermal studies on explosives show some time-temperature equivalence to apply (see for example [HEN 06]), enabling us to infer the ignition temperature once the time to ignition is known. For the case of impact loading (either low or high velocity), it is easy to estimate the macroscopic temperature rise due to quasi-adiabatic self-heating, and thus to guess the ignition time. Very strong discrepancies are then observed between guessed and measured ignition times, suggesting that macroscopic temperature is not the relevant parameter for ignition predictions.

Given the highly heterogenous nature of energetic materials, it is inferred that the local (or microscopic) temperature should rather be considered, thus putting forward the concept of "hot spots", that is, local temperature peaks around which exothermic chemical reactions first take place [BOW 52]. This shows clearly that a purely macroscopic treatment of impact-induced explosions is not relevant, and that a microstructure-based modelling effort should also be undertaken. The long-term goal of the present study is therefore to build physically-based tools to predict the occurrence of explosions in response to low velocity impacts, in a pressed explosive whose microstructure and macroscopic behavior are described in the next section.

For this purpose, the small scale ignition processes must be identified. Unfortunately, experimental efforts have as yet been unsuccessful due to insufficient spatial and temporal instrumental resolution available to date. It must be realized that local heating is the result of a competition between dissipative processes and small-scale thermal conduction, such that the scale of hot spots depends on the time scale of the external loading process. Hence, combined experimental and theoretical works suggested three possible ignition micromechanisms, namely, viscoplastic pore 
collapse for the high velocity impact case, closed microcrack friction and grain (visco)-plasticity for the low velocity one [FIE 92, DIE 96, COF 98]. This must be at most considered as reasonable guesses, and requires experimental verification.

\subsection{Methodology}

Real-time and small-scale observations are clearly required. However, due to the the present unavailability of relevant instruments, an alternative methodology is adopted here, based on post-mortem microstructural analysis of recovered samples. It should be emphasized that mechanical and chemical micro-processes very likely depend on the applied load. Hence, the following two-fold method is used. Firstly, hot spot ignition is not an immediate process; in other words, hot spots may die away if the self-heating process is not sufficiently sustained. Such extinguished features should contain very useful information; hence, recovering and analyzing a target impacted at a velocity close to but below the explosion threshold is the first objective. However, accumulated experience has shown such objects to contain a huge amount of information, difficult to analyze due to superposition of sequential mechanisms. Simpler objects must therefore be produced and studied. For this purpose, relevant solicitation ranges have first to be determined. Then, dedicated "unitary" laboratory experiments are performed, and samples recovered after simple and well known loading in the relevant range. In the present case, given the nature of the material at hand, the main parameters examined will be pressure and strain-rate, spanning from 0 to a few $\mathrm{GPa}$ for pressure, from 0 to $10^{4}-10^{5} \mathrm{~s}^{-1}$ for strain rate.

The analysis of recovered sample employs optical microscopy (see for example [SKI 99, DEM 98]), and remains essentially qualitative. This method has several advantages, among which the possibility to choose, in position and orientation, observed surfaces. Given the depth of field of optical microscopes, careful polishing is required. This is done on vacuum-epoxy mounted samples, ensuring that no (or at least well identified) artefacts are introduced during the surface preparation. This is generally not the case when scanning electron microscopes are preferred. A carefully designed metallographic or petrographic-like polishing protocol is followed, neither surface etching nor ultrasonic surface cleaning is necessary.

The results of systematic investigations are presented below. The description of altered microstructures, as well as the subsequent analyses, are principally founded on morphological findings solely. It is clear that further work should involve analytic physico-chemical and crystallographic methods to get a sounder understanding of deformation and reaction processes. 


\subsection{The material: microstructure and macroscopic mechanical behavior}

The energetic material considered here is a HMX-based pressed explosive ${ }^{1}$. It contains approximately 6 (vol.) \% elastomer binder, and its global porosity is around $1 \%$. Figure 9.1 shows a low magnification example of its initial concrete-like microstructure. It consists of large (often) polycrystalline grains, embedded in a composite matrix, itself a mixture of smaller grains, the binder and the porosity, which appears as black dots in the micrograph of Figure 9.1. HMX grains appear to be almost pore free.

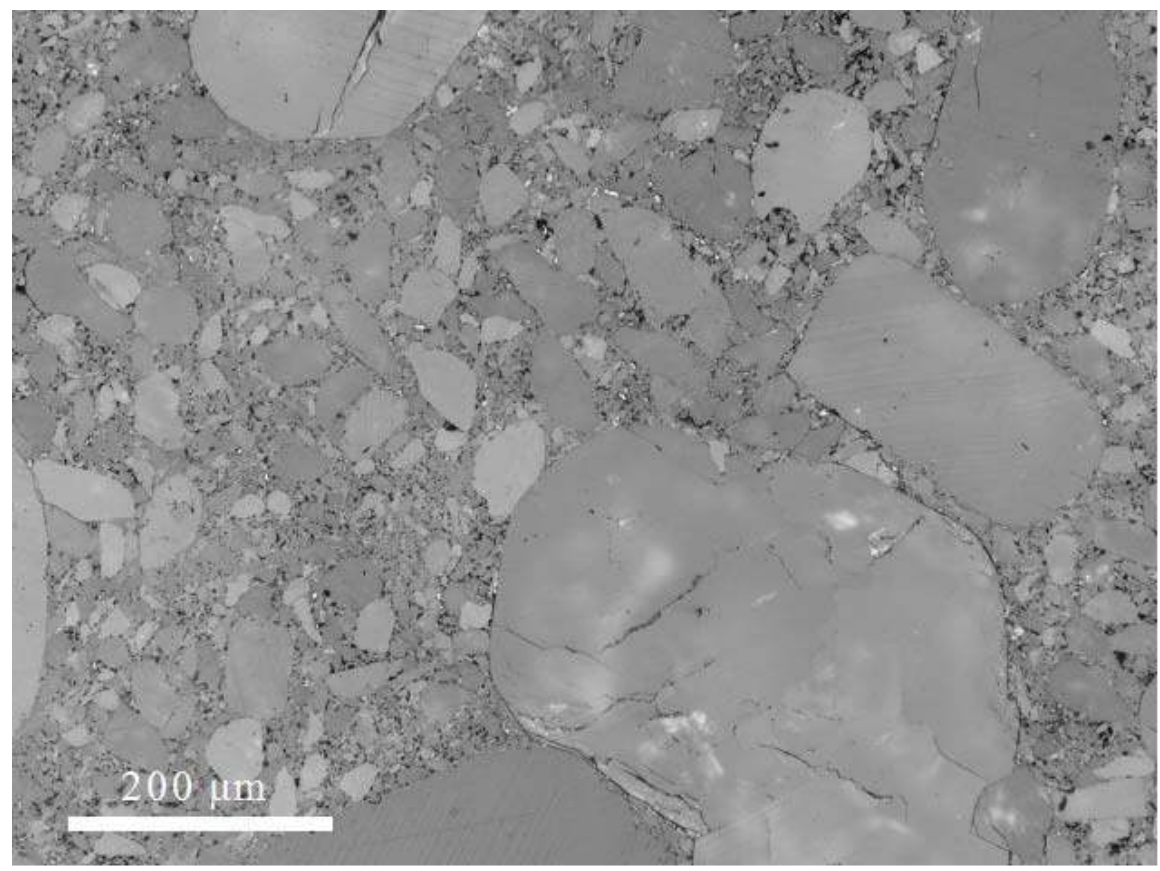

Figure 9.1. Polished cross-section of the pristine material seen under reflected polarized light with the optical microscope, typical concrete-like texture

It should be emphasized that this so-called pristine microstructure is not free from defects. Large grains contain intra- and trans-granular microcracks. As the starting HMX powder (not shown) is defect-free, one concludes that microcracking stems from the isostating pressing process. A careful examination of virgin samples shows that micro-cracking is due to large grains mutual contacts. Some deformation bands are also observed in many grains. Some grain-matrix debonding is visible as dark parts on the grain perimeter. Hence, grain-matrix interfaces are likely to be weak.

This material was submitted to various unitary mechanical laboratory tests: uniaxial and triaxial quasi-static compression and uniaxial dynamic compression.

1. HMX (for High Melting-point eXplosive), or tetrahydro-1,3,5,7-tetranitro-1,3,5,7tetrazocine, is one of the most powerful explosives to date. 


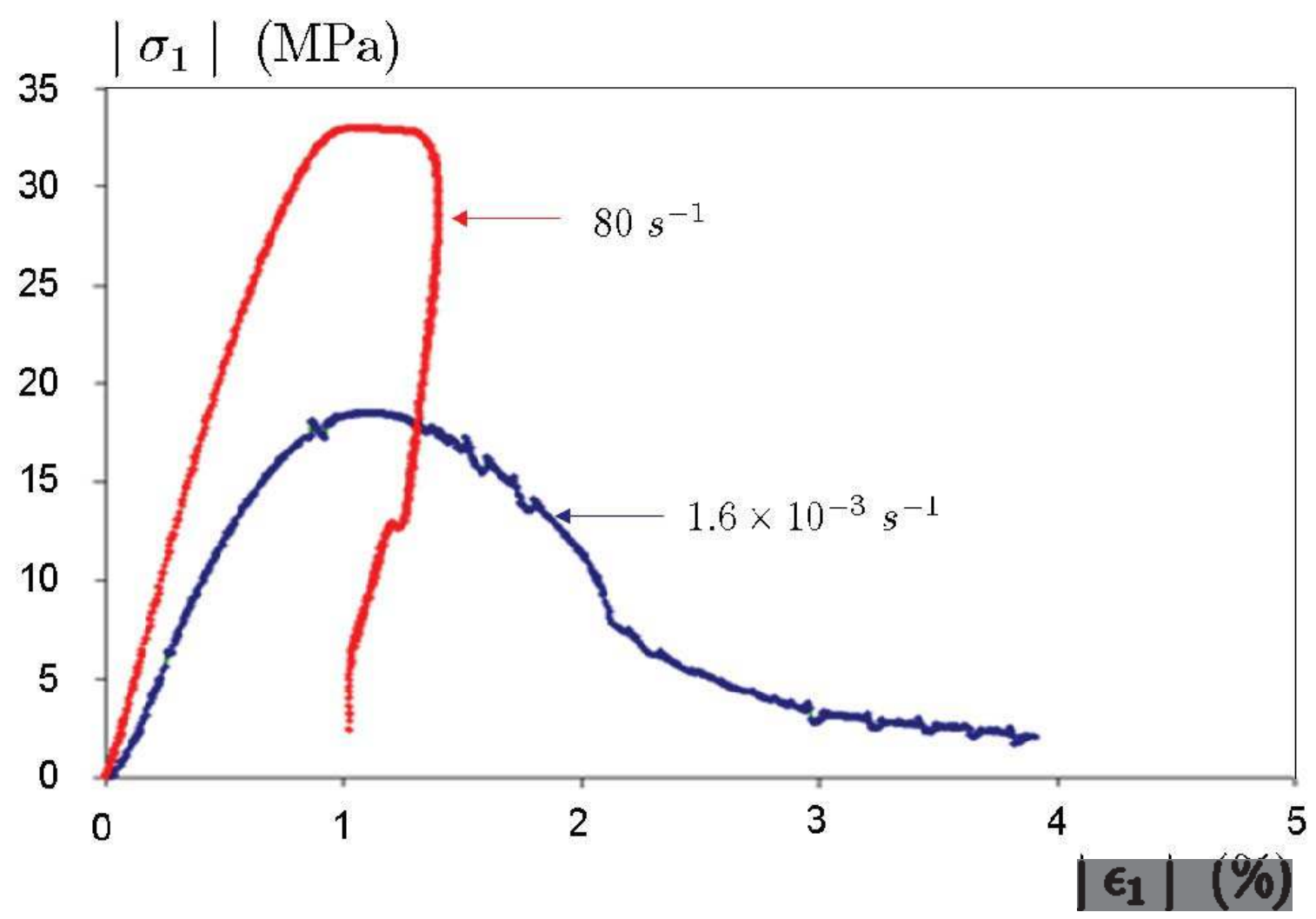

Figure 9.2. Material response in uniaxial quasi-static and dynamic compression

The mechanical behavior displayed in Figures 9.2 and 9.3 is typical to that of a viscous rock-like material. Under low confining pressure (Figure 9.2), quasi-brittle (i.e. viscoelastic ${ }^{2}$-damage) behavior is recorded. In this case, a peak stress and subsequent softening are observed, and the material only sustains a few percent strain at most. The value of the peak stress is highly rate sensitive, indicating viscosity, but ductility is not increased. The softening part of the stress-strain curves is associated with mechanical instability and strain (and damage) localization, in the form of macro-cracks. The formation of those cracks and their type (axial splitting or shear cracks) depends strongly on boundary conditions at the sample edges.

If hydrostatic pressure is superimposed on a uniaxial stress state (triaxial stress state), a brittle to ductile transition is observed to take place for a confining pressure lower than $20 \mathrm{MPa}$ approximately. Together with softening inhibition, a strong increase to the load bearing capability of the material, as well as its ductility, are observed. Unfortunately, due to apparatus shortcomings, axial strain remained limited to $20 \%$, and it was possible neither to control nor to record the unloading phase of the triaxial tests.

2. Contrarily to propellant-like materials, for which very strong viscoelasticity is observed, the present material displays only weak, despite of being strongly non-linear, viscoelasticity [GRA 09]. 


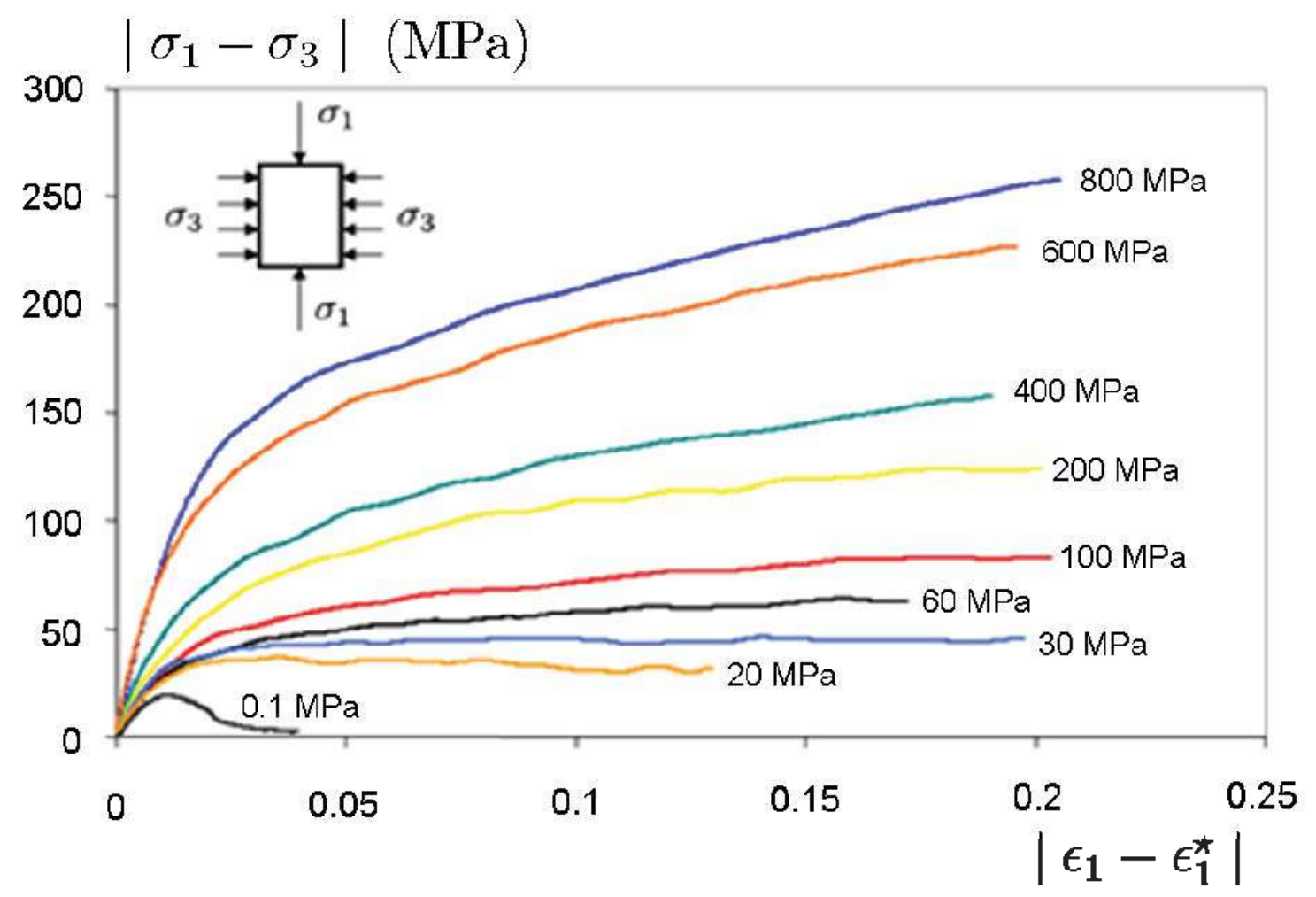

Figure 9.3. Material response in triaxial quasi-static compression ${ }^{3}$

Above $20 \mathrm{MPa}$ confining pressure, the overall longitudinal behavior is plastic like with very limited softening at $20 \mathrm{MPa}$, perfect plasticity at $30 \mathrm{MPa}$ and hardening above. Besides, it is interesting to follow volume variations, as displayed in Figure 9.4 below. It is seen that, although hardening behavior is obtained at $60 \mathrm{MPa}$ confining pressure, volumetric softening (dilation) occurs nevertheless. The $100 \mathrm{MPa}$ case somewhat appears as a transition. Above this value, all samples undergo compaction, except at very high pressures, for which constant volume plasticity is recorded.

Since unloading could not be recorded, the samples were measured after each experiment, indicating essentially elastic unloading. However, slow recovery was observed for all the samples, examined several months after their recovery. Delayed recovery was almost total for low confining pressures, and quite negligible for high ones. A high pressure purely hydrostatic experiment underwent full recovery as well.

3. The triaxial compression experiment consists of two phases. The sample is first hydrostatically loaded up to the pre-selected confining pressure. The symbol $\varepsilon_{1}^{*}$ represents the longitudinal strain reached at the end of this hydrostatic phase. The sample is then longitudinally compressed, the lateral stress being kept at the confining pressure. The plot of Figure 9.3 gives the triaxial response of the material, that is measured from the end of the hydrostatic phase. 


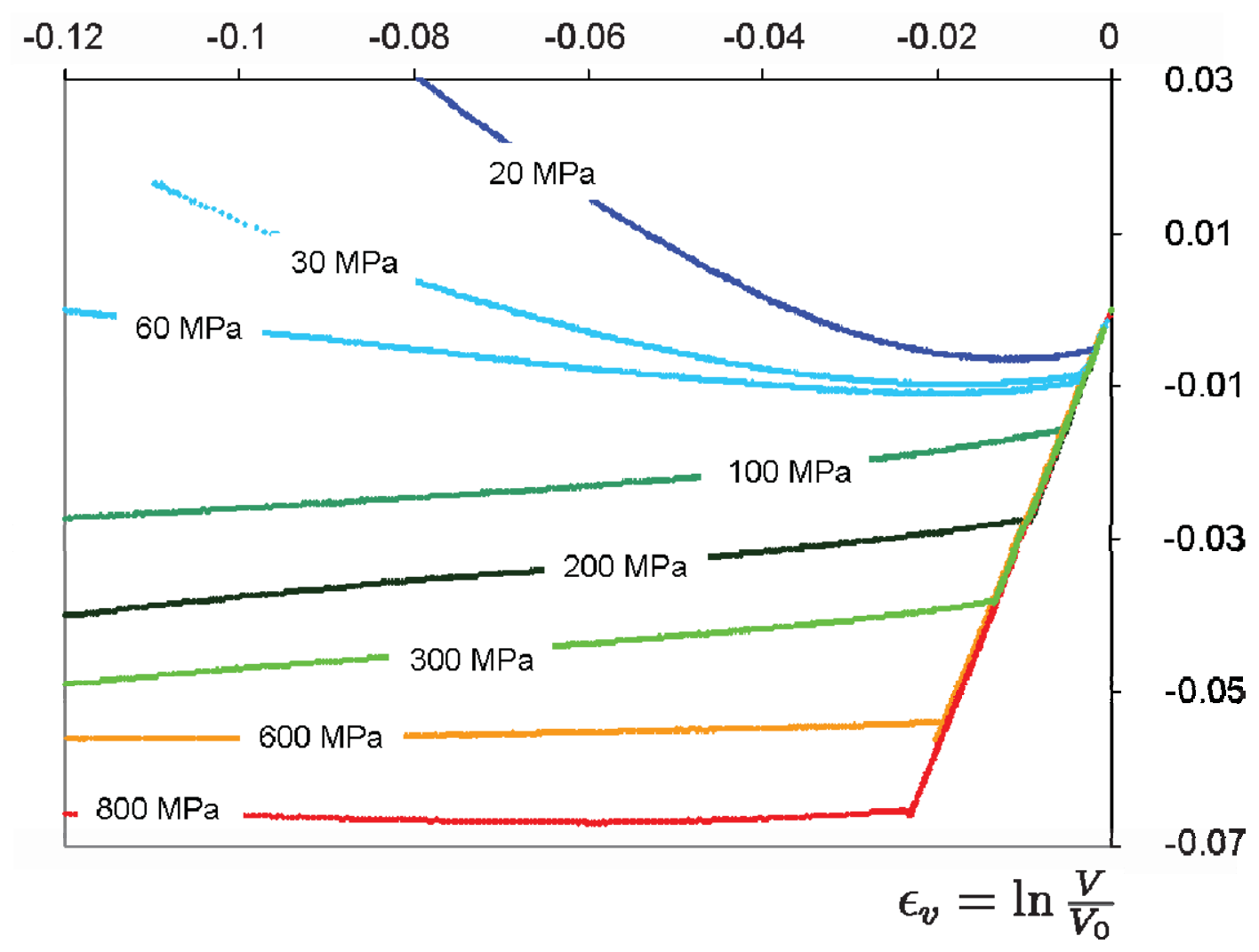

Figure 9.4. Volume variations during quasi-static triaxial experiments

\subsection{Samples from unitary experiments}

Samples were recovered after all above-mentioned experiments. Thorough investigations showed the following mechanical processes to occur: grain-matrix debonding, intra- and trans-granular micro-cracking, grain plasticity in the form of deformation bands and matrix modifications. Small scale coalescence was also observed, as well as macro-cracking and other kinds of localization processes.

\subsubsection{Uniaxially loaded samples}

Elementary deformation processes in uniaxially loaded samples are essentially grain-matrix debonding and grain micro-cracking. On fully unloaded post-mortem samples, debonding crack opening is quite small, and can only be seen as enhanced grain boundaries.

In quasi-statically loaded samples, platen-sample friction could not be avoided, and only the central part of $10 \mathrm{~mm}$ diameter $-20 \mathrm{~mm}$ length samples is nearly homogenous, displaying extensive randomly oriented intra-granular micro-cracking (Figure 9.5, left view). Figure 9.2 shows that maximum stress occurs at roughly 1\% axial strain, and that softening subsequently occurs. This softening behavior is associated with a damage localization process. Samples unloaded from the 
maximum stress state showed incipient micro-crack coalescence took place (Figure 9.5, right view), mainly by local linking through the matrix, to form strongly oriented intermediate size objects, referred to as "meso-cracks" in the sequel. Continued loading end up with macro-cracks, generally consisting in finite width localized micro-crack arrays with large residual openings. Macro-cracks eventually meet and result in strongly strained zones, where clear thermal effects could be detected. This is further commented upon in section 9.4.3.
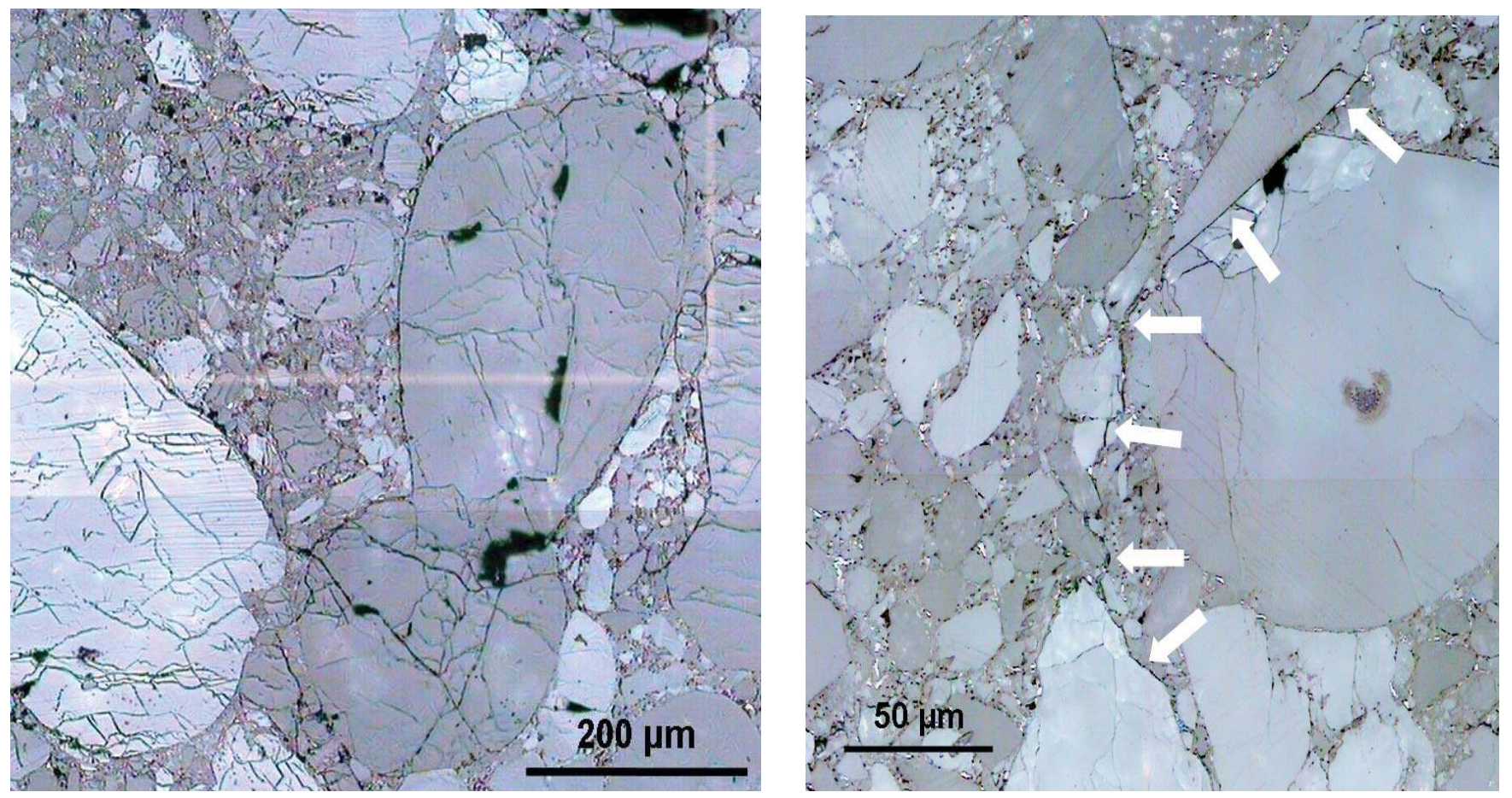

Figure 9.5. Polished cross-section of a sample recovered after uniaxial quasi-static compression, seen under reflected polarized light with the optical microscope. Left: central part of the sample loaded to 4\%, extensive intra-granular micro-cracking. Right: sample unloaded at $1 \%$ strain, onset of mesoscopic coalescence (arrows)

In the dynamically loaded well lubricated sample, strongly oriented intragranular micro-cracking is systematically observed with crack normal oriented according to positive macroscopic strain, as shown in Figure 9.6 (left view), taken in the axial plane. Damage-induced orthotropy is clear, as ortho-axial observations (Figure 9.6, right view) show no preferential crack orientation. The sample was unloaded at ca. $1.5 \%$ axial strain, and macro-cracking had time to develop. This results in an array of macro-craks relatively evenly spaced, with a mean inter-crack spacing of ca. $5 \mathrm{~mm}$. Between two adjacent cracks, sub-arrays of smaller ones can be found, with spacing of ca. $2 \mathrm{~mm}$. Examining an ortho-axial surface reveals these arrays as more or less square inter-twinned networks (white dotted squares in Figure 9.6, right view). Clearly, radial and circumferential macro-cracks intersect together, showing that the state of strain is almost equi-biaxial and homogenous. 

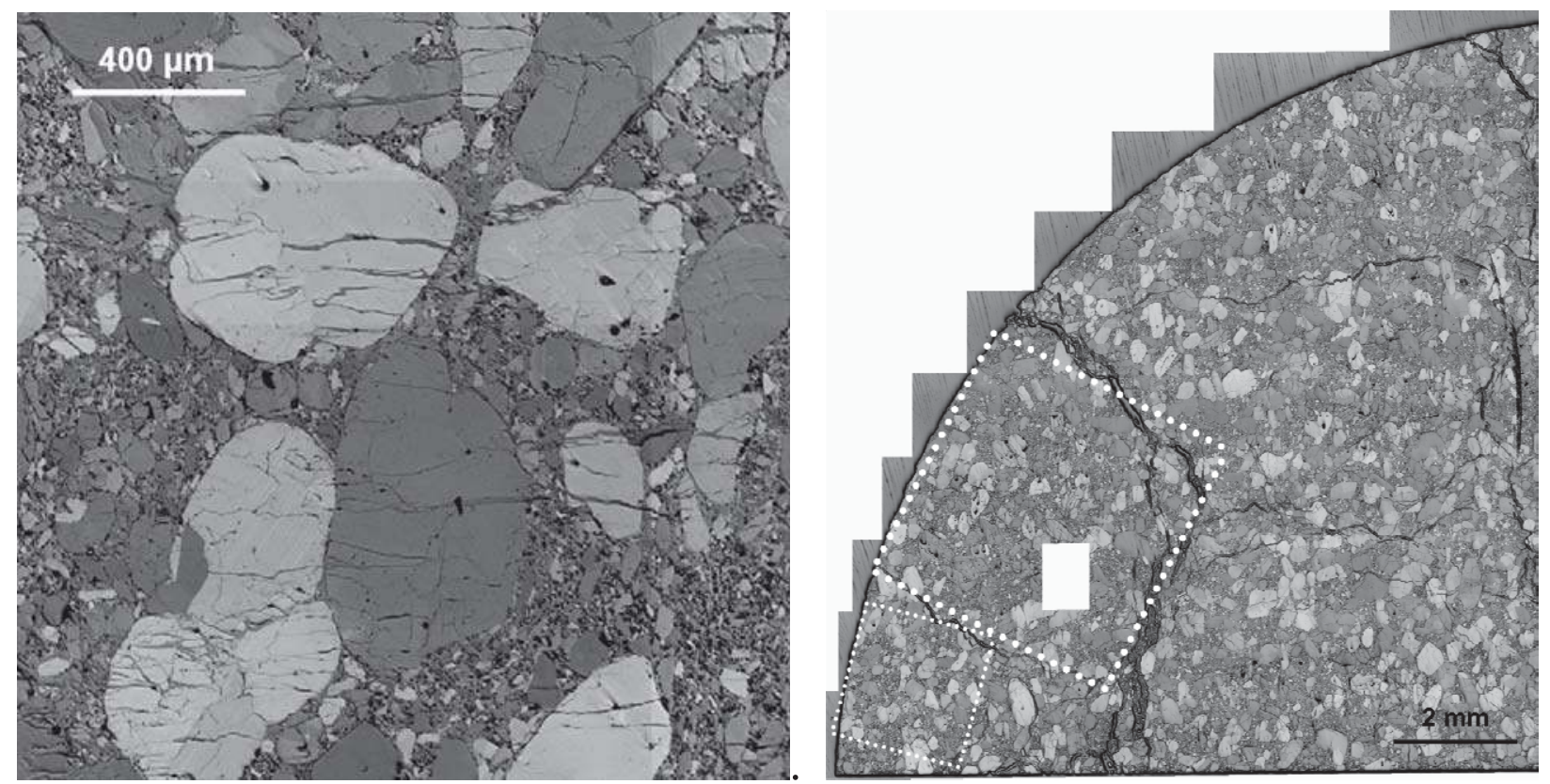

Figure 9.6. Polished cross-section of a sample recovered after uniaxial dynamic compression, seen under reflected polarized light with the optical microscope. Left: axial view, showing strongly oriented trans-granular micro-cracking. Right: ortho-axial view, showing radial and circumferential crack network (dotted squares)

\subsubsection{The effects of confining pressure}

Figure 9.3 clearly shows the very strong effect of superimposed pressure on the mechanical behavior of un-lubricated samples. Not only does pressure induce a strong increase of material strength, but also does it enhance ductility. The classical brittle-to-ductile transition takes place between 10 and $20 \mathrm{MPa}$ confining pressure, conferring to this material a typical concrete-like behavior.

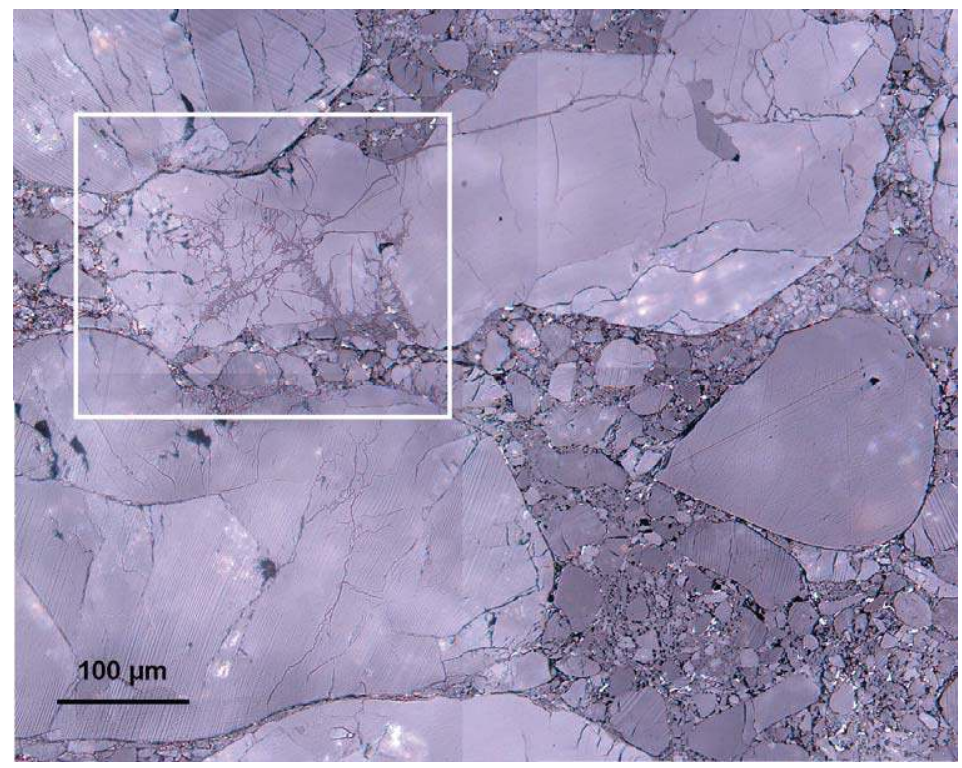

Figure 9.7. Polished cross-section of a sample recovered after triaxial quasi-static compression (20 MPa confining pressure) seen under reflected polarized light with the optical microscope. See Figure 9.10 for the detail indicated by the white rectangle 
The $20 \mathrm{MPa}$ confining pressure sample displays smooth gradients. Near the sample edges, the microstructure is absolutely undisturbed. Except in the vicinity of the symmetry plane, a homogenous microstructure is observed (Figure 9.7). It is characterized by an enhanced density of intra- and trans-granular micro-cracks, with no apparent orientation, and an increase of the deformation band density. A relative abundance of closed crack sliding is observed, but with small relative displacement. Also, grain contact cracking is often replaced by a less localized process, referred to as "grain buckling" in the sequel, illustrated in Figure 9.8. Strains appear to be localized in relatively broad bands. Since this process was only observed at moderate confining pressure $(20-60 \mathrm{MPa})$, it can be used as a qualitative pressure probe.

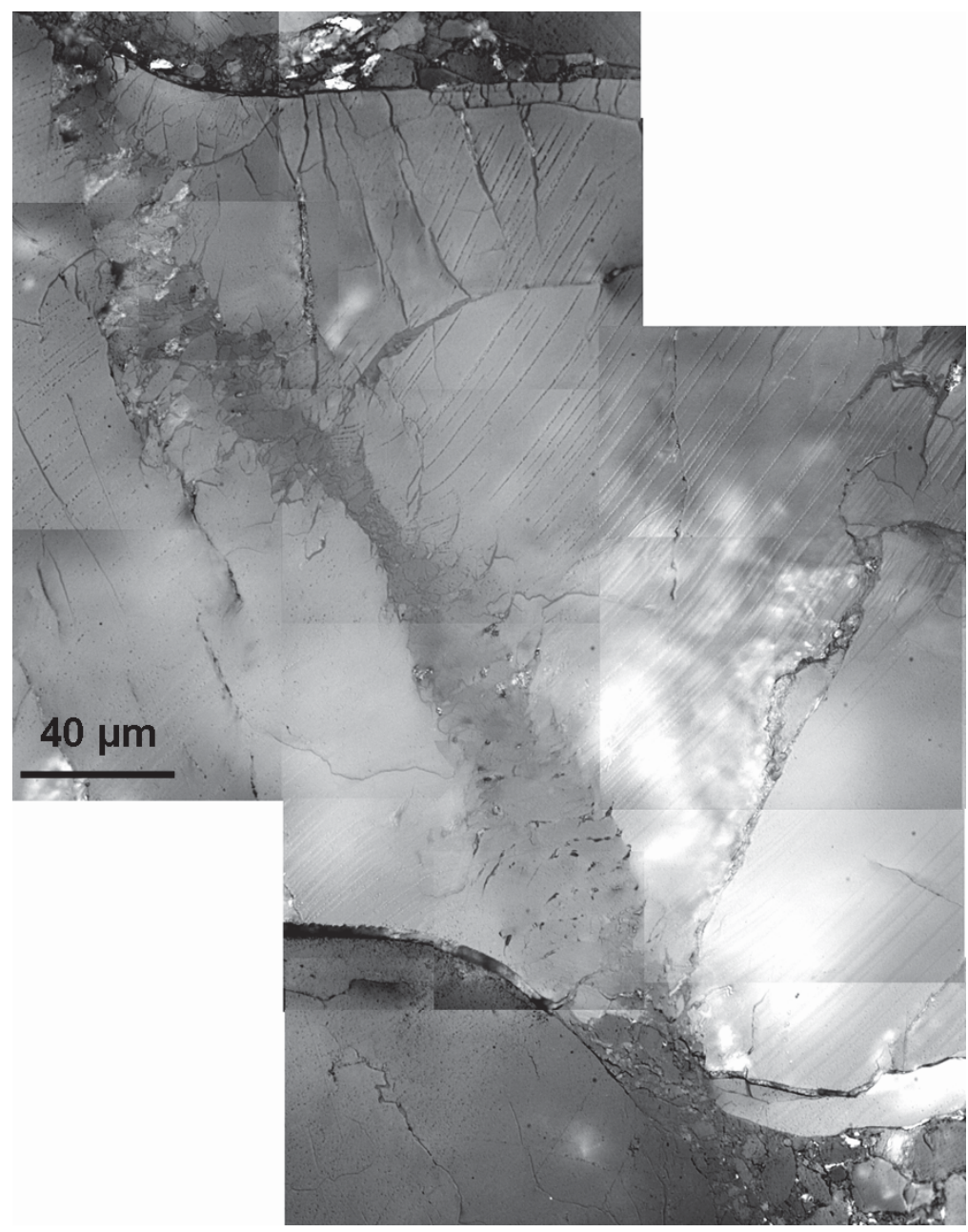

Figure 9.8. Polished cross-section of a sample recovered after triaxial quasi-static compression (20 MPa confining pressure) seen under reflected polarized light with the optical microscope. Example of grain buckling

Finally, this sample shows a very interesting feature near its symmetry plane, namely, a zone of a few millimeters thickness of localized barrelling. The densities of micro-cracking and deformation bands are stronger, and this zone also contains thermal features described in section 9.4 .3 below. 
At high confining pressures (i.e. above $200 \mathrm{MPa}$ ), grain micro-cracking almost completely disappears, being replaced by extensive grain plasticity (Figure 9.9, left view). The latter is strongly oriented in the straining direction (indicated by grain flattening), and forms deformation bands. At moderate confining pressure, essentially narrow bands are observed. They appear to widen at higher pressure; the resulting wide bands are observed to contain smaller ones of different orientations (Figure 9.9, right view). From the observation of the microsections of the various samples it is shown that a direct relation links the density of deformation with the confinement and an inverse relation with the density of fractures.

Changes of the aspect ratio of the grains and changes of their orientations are observed above $60 \mathrm{MPa}$ and are very significant at $800 \mathrm{MPa}$. Grains flatten and tend to align their long axis perpendicularly to the direction of the longitudinal load. Eventually, micro-cracking takes place across some bands, presumably when the banding process saturates and displays no more strain accommodation capability.
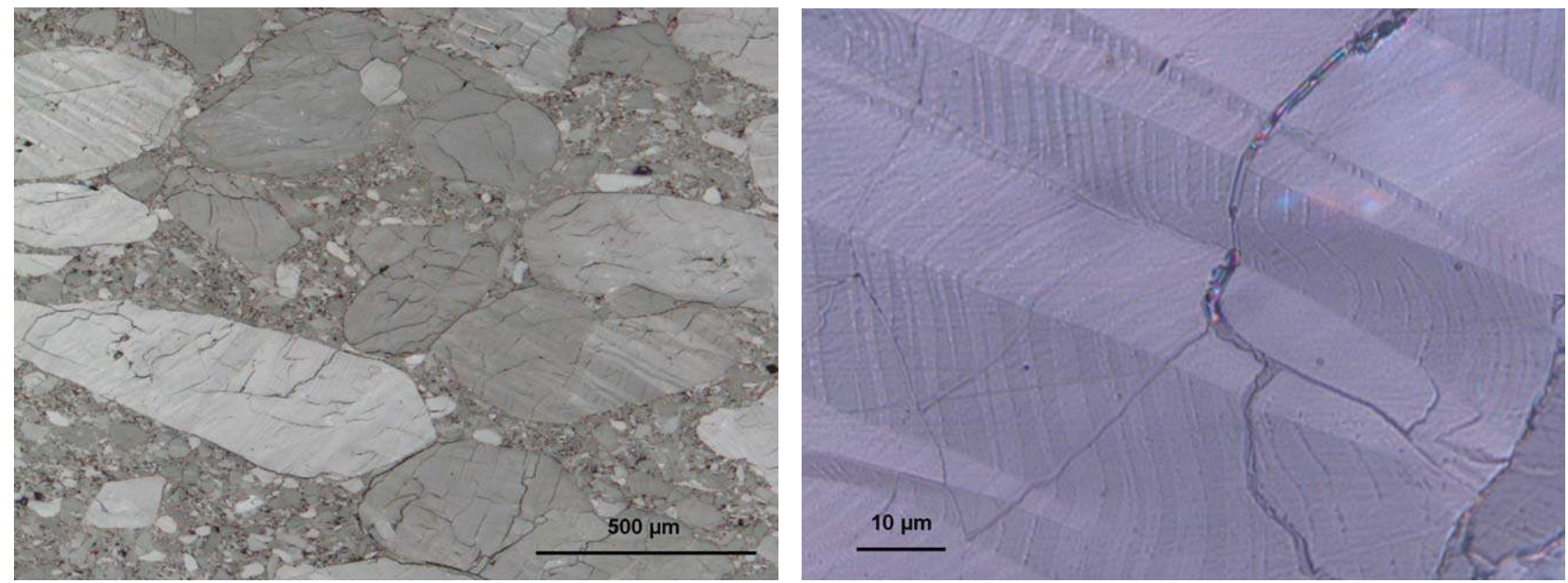

Figure 9.9. Polished cross-section of a sample recovered after triaxial quasi-static compression (800 MPa confining pressure) seen under reflected polarized light with the optical microscope. Left: general view, with elongated grains containing numerous large deformation bands. Right: high magnification, showing 2 families of deformation bands, the densest and thinnest ones being reprocessed by the largest one in a distinct orientation

It should also be added that the manufacturing process involves relatively high quasi-isostatic pressing (approximately $150 \mathrm{MPa}$ ), clearly responsible for intra- and trans-granular micro-cracking, and for deformation banding as well. For verification purposes, a sample hydrostatically loaded to $800 \mathrm{MPa}$ was also investigated. Hardly, any difference could be noticed from the initial microstructure displayed in Figure 9.1. It was observed that the porosity totally disappears above $200 \mathrm{MPa}$; it could be shown that the subsequent loading curve follows closely that of pure HMX. Two consequences can then be drawn: (i) pore closure is a reversible process, since the observed resulting microstructure does display matrix porosity and (ii) the binder plays no active role in strain accommodation above $200 \mathrm{MPa}$; this is presumably the 
effect of grain "locking", due to strong frictional grain-grain contacts, considering the little amount of binder (around 6 vol. $\%$ in the undeformed material, approximately twice this amount in the sole matrix).

Recovered sample observations show that pressure inhibits micro-crack coalescence in a quite progressive fashion, and favors the development of grain plasticity. At low confining pressure (i.e. below $60 \mathrm{MPa}$ ), coalescence is not fully inhibited, although only very limited localization at sample corners is eventually found.

\subsubsection{Non-mechanical processes}

Although none of the above described samples were thermally loaded, nonmechanical (i.e. thermal) features were found in some of them. Essentially four types of manifestations can be distinguished, namely solid-solid phase transformation, melting, solid-gas reaction, and liquid-gas reaction. It should be understood that the results presented herein are essentially interpretations. Analytic analysis methods were only used to identify phase transformation induced manifestations on thermally loaded samples (see below).

The first of these manifestations is voids, generally associated with intra-granular micro-cracks. Voids are characterized by curved contours. They mainly occur at the termination of the micro-cracks (see arrows in Figure 9.10, left view), or at or near bifurcation points. The cavities are attributed to material loss, as result of punctual reaction along the discontinuity. The lack of melt, glass, bubble decorating the cavities strongly suggest the reaction is not involving passage at the liquid stage. Voids are thus interpreted as result of a solid-gas reaction. The left view of Figure 9.10 gives an example found near a sample boundary in the pristine material. The reaction is attributed to sample machining. The discontinuities decorated by these voids are far from being rectilinear, and will be referred to as "worm-like cracks" in the sequel. Very large worm-like crack densities can be achieved, often in crushed grains, as shown in the right view of Figure 9.10 below. These manifestations are quite frequent in the loaded specimen, except in those confined at very high pressure.

Evidence of melting is also found, as illustrated in Figure 9.11, taken from the 20 MPa triaxial recovered sample, and signalled by white arrows. Melting is attested by the position (infillings), the morphology (elongated flowed contours) and the texture (presence of frozen bubbles), all implying passage to liquid state and flow. They clearly result from melting. Their position does not necessarily sign a hot spot as they can be transported owing to intrinsic properties of liquid and to indirect evidence of circulating gas responsible for the voids mentioned above. 

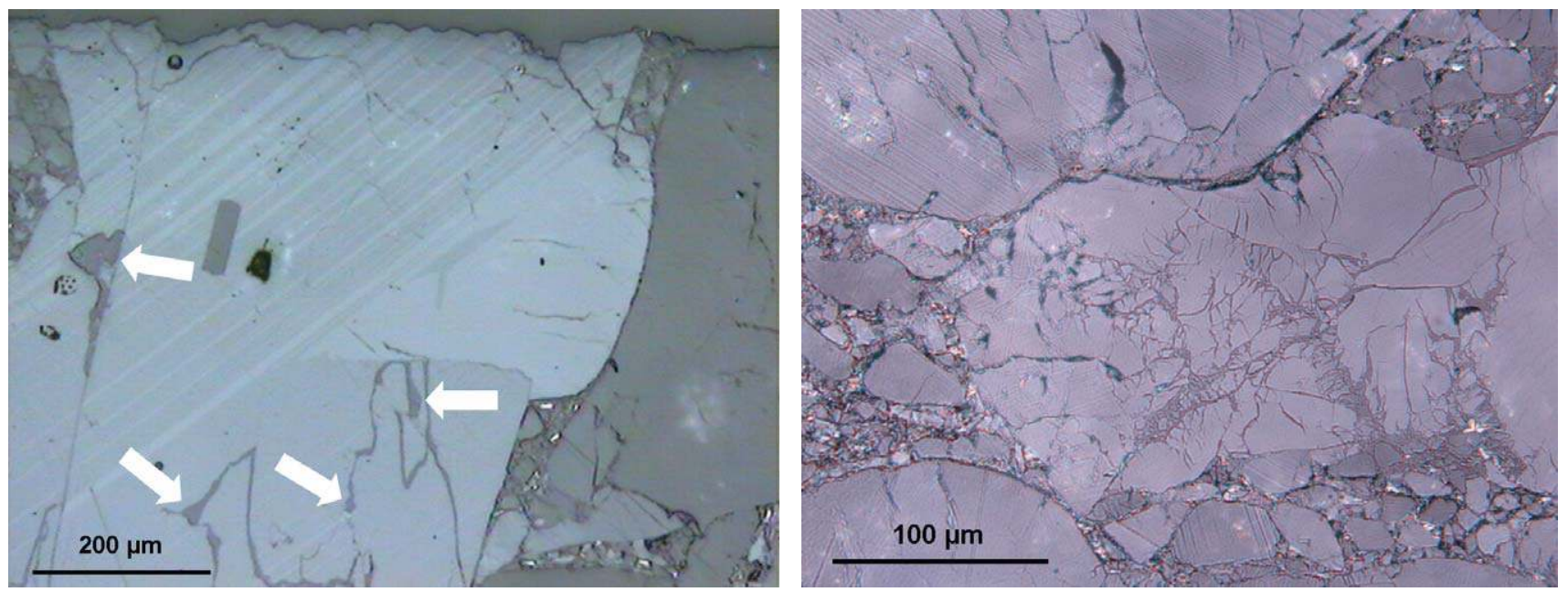

Figure 9.10. Polished cross-section under reflected polarized light with the optical microscope. Left: pristine material near the machined edge of the sample (top) displaying typical worm-like crack locally reacted (arrows). Right: sample recovered after triaxial quasi-static compression (20 MPa confining pressure) displaying reacted microcracks

The melt is presumably quenched in a glassy state upon unloading. Bubbles are interpreted as a liquid-gas reactive process. HMX is known to melt at $280^{\circ} \mathrm{C}$, and liquid HMX is known to be quite unstable and to decompose quickly into gas species.

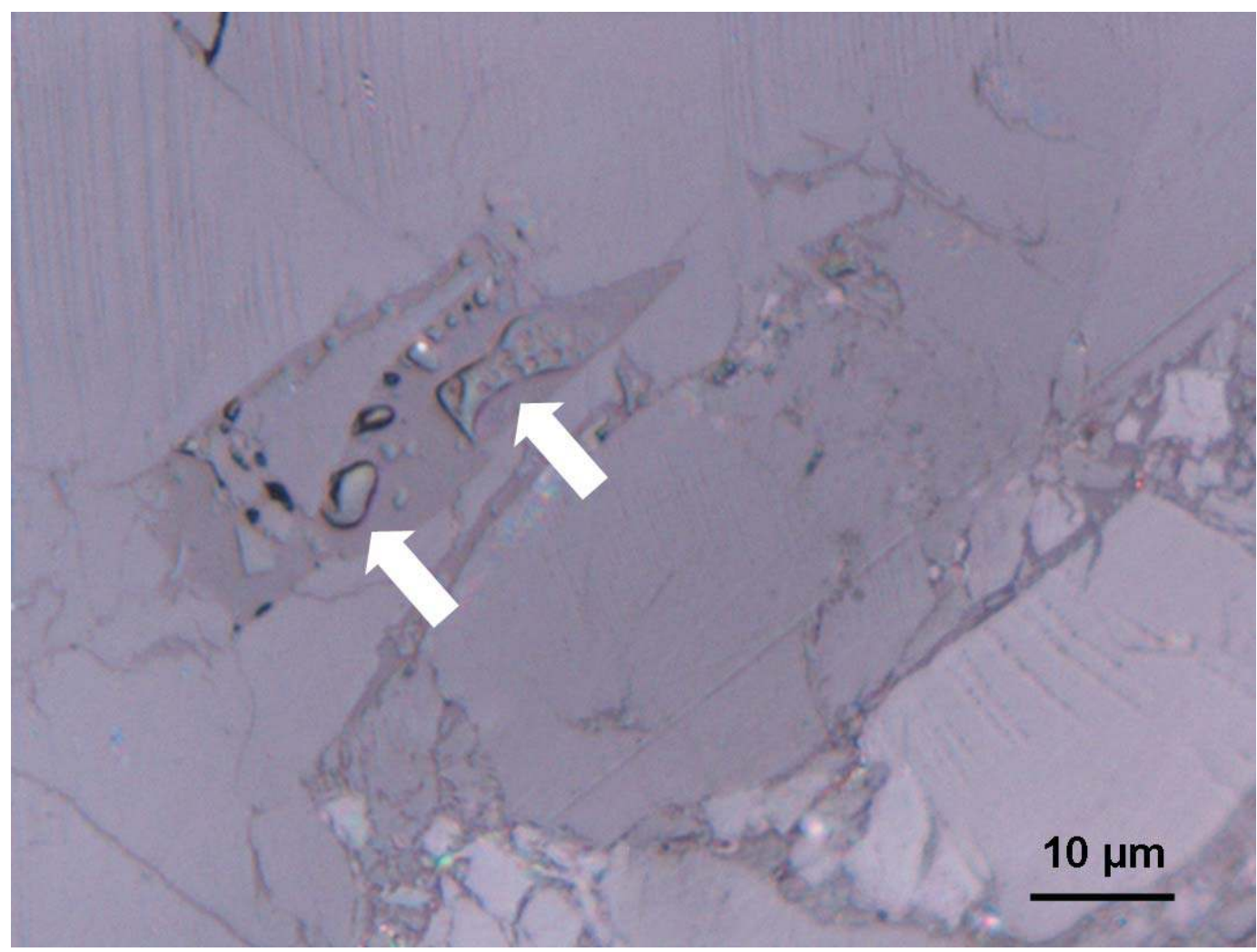

Figure 9.11. Polished cross-section of a sample recovered after triaxial quasi-static compression (20 MPa confining pressure) seen under reflected polarized light with the optical microscope. Example of melted figures (white arrows) 
The last type of thermal manifestation is the solid-solid phase transformation. The stable form of HMX at ambient temperature is monoclinic (beta-phase), undergoing a transition to a hexagonal form (delta phase) at around $150^{\circ} \mathrm{C}$ under very slow heating. The high temperature form is metastable upon cooling, and can be observed easily in recovered samples. Figure 9.12 shows the microstructure of a sample slowing heated to $150^{\circ} \mathrm{C}$, maintained at this temperature for 10 minutes, then slowly cooled.

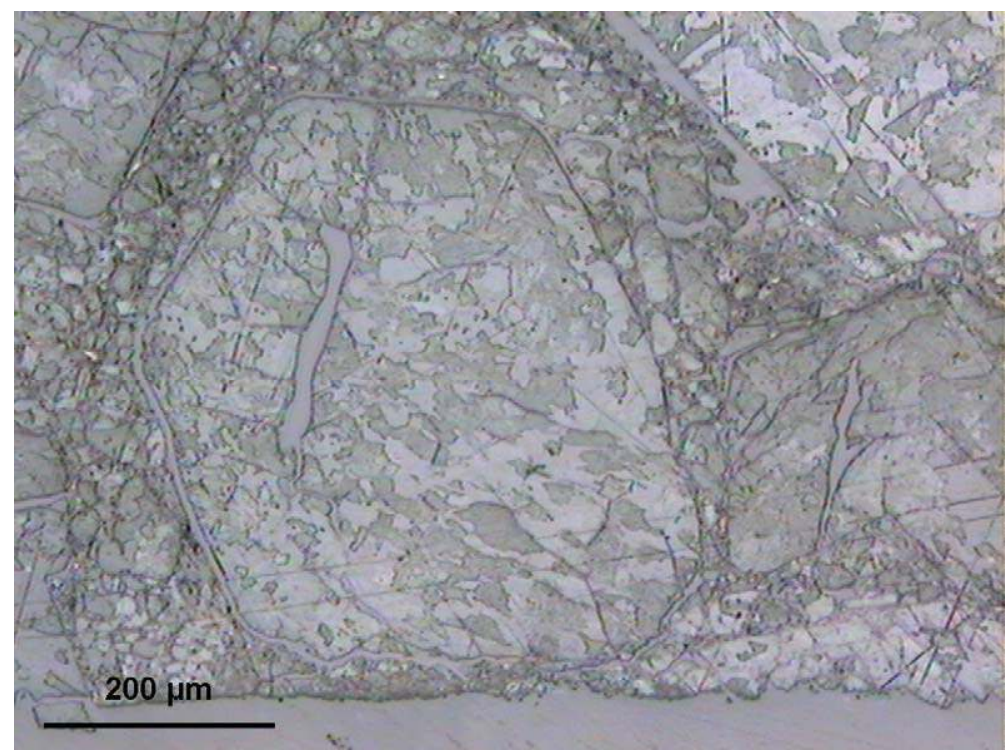

Figure 9.12. Polished cross-section of the recovered thermally cycled sample seen under reflected polarized light with the optical microscope. Total debonding and solid-solid phase transition recrystallization patterns

This sample displays almost total debonding of the largest grains, together with a characteristic recrystallization pattern. It was verified that both beta and delta phases coexist in this sample using FTIR microscopy. When the size of the domain decreases (in relation with the cooling conditions), the patchwork texture becomes unresolved under the optical microscope, resulting in a "cloudy" aspect (examples observed in the recovered target, see below).

The comparison of the various experiments clearly shows a striking result, namely, an inversed relationship between reaction and confining pressure. The confining pressure seems to prevent reaction. No sign of reaction is observed in the most highly confined experiments $(200-800 \mathrm{MPa})$. Conversely the most abundant evidences and the largest diverstity of reaction are observed in the least confined experiments (20-60 MPa). The most pronounced effects are material losses, that is, solid-gas reactions. They develop along all types of intragranular cracks and fractures in the large grains. They also affect the periphery of the small grains in the matrix resulting in a significant increase of the porosity both in the grains and in the matrix. Melting is also observed mainly in the matrix and is apparently much more limited than solid-gas reaction. 


\subsection{Analysis of a recovered target}

A series of low velocity impact shots was realized [DEL 07, GRU 09], involving a rigid $56 \mathrm{~mm}$ diameter steel projectile fired on steel-encased explosive targets. The explosive sample was confined onto all its external boundaries by heavy steel plates, except on its impacted surface, only confined by a $3 \mathrm{~mm}$ thick steel plate. For this target and impactor geometries, an explosive response of the target was recorded for impacts above $76 \mathrm{~m} . \mathrm{s}^{-1}$, whereas a non-exploded targed could be recovered for an impact velocity of $58 \mathrm{~m} \cdot \mathrm{s}^{-1}$.

The target was carefully vacuum epoxy impregnated prior to cutting, according to Figure 9.13. A thin slice was selected and prepared so as to provide a surface containing the penetration axis (axial surface).

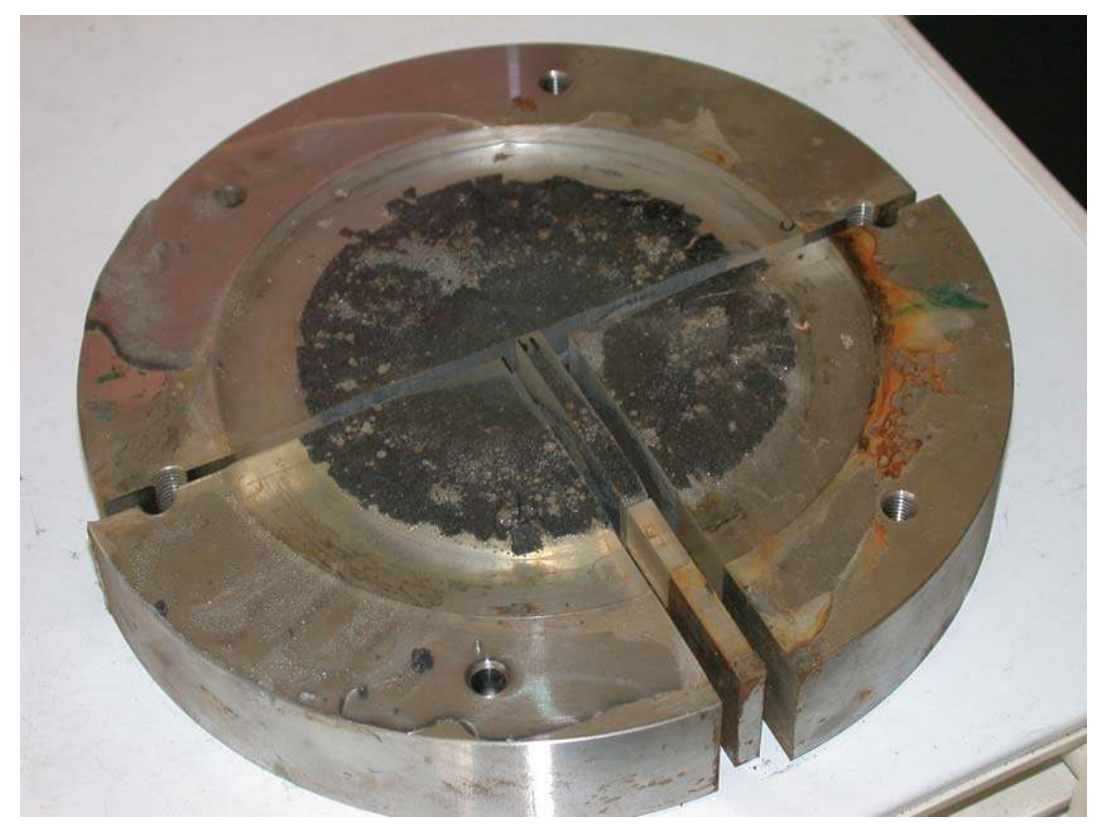

Figure 9.13. General macroscopic view of the recovered target and saw cut for further preparation of polished cross-section (see Figure 9.14)

Figure 9.14 shows an overview of the sample at very low magnification, clearly displaying the crater. Dark areas correspond to zones containing more expoxymounting resin that the average. Some macro-cracks are visible as dark lines, although most of them only appear at greater magnification.

For this target geometry, it is known (see [DEL 07, GRU 09]) that ignition takes place on the impact axis. The central zone can thus be interpreted as the remnant of an ignition process which did not go to deflagration, due to insufficient loading duration and/or intensity. This zone (Figure 9.15) is therefore first investigated in the recovered target. 


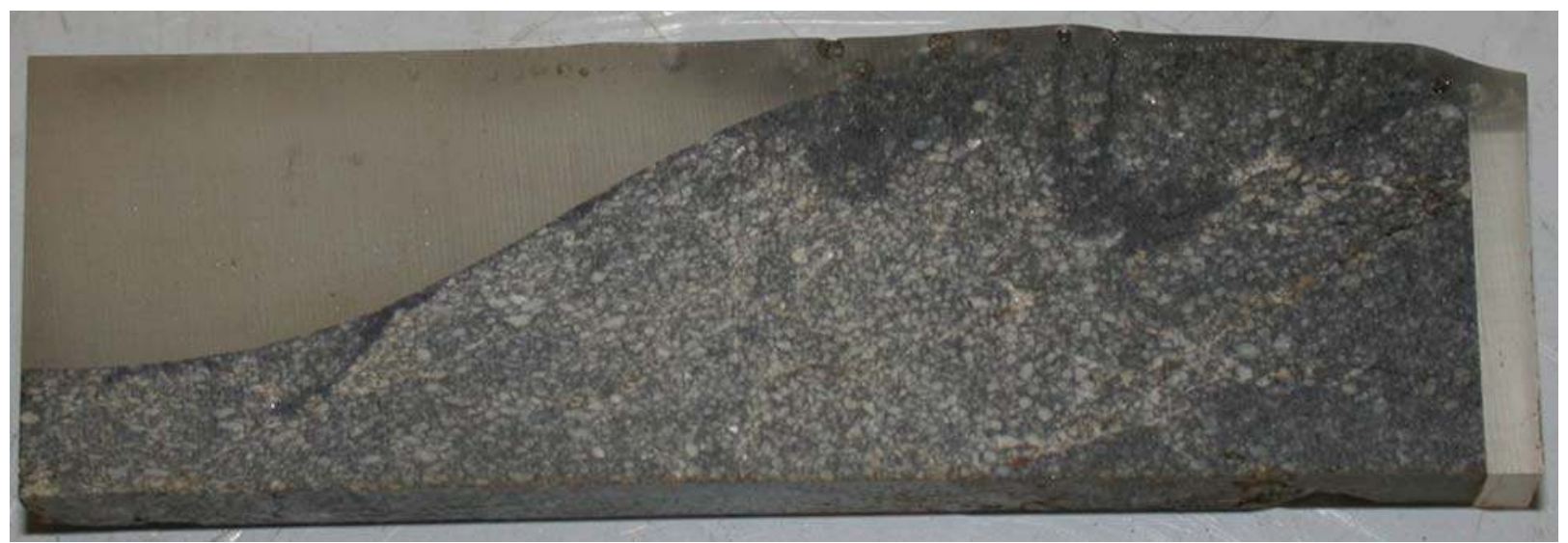

Figure 9.14. Macroscopic view of the cross-section slab before final polishing

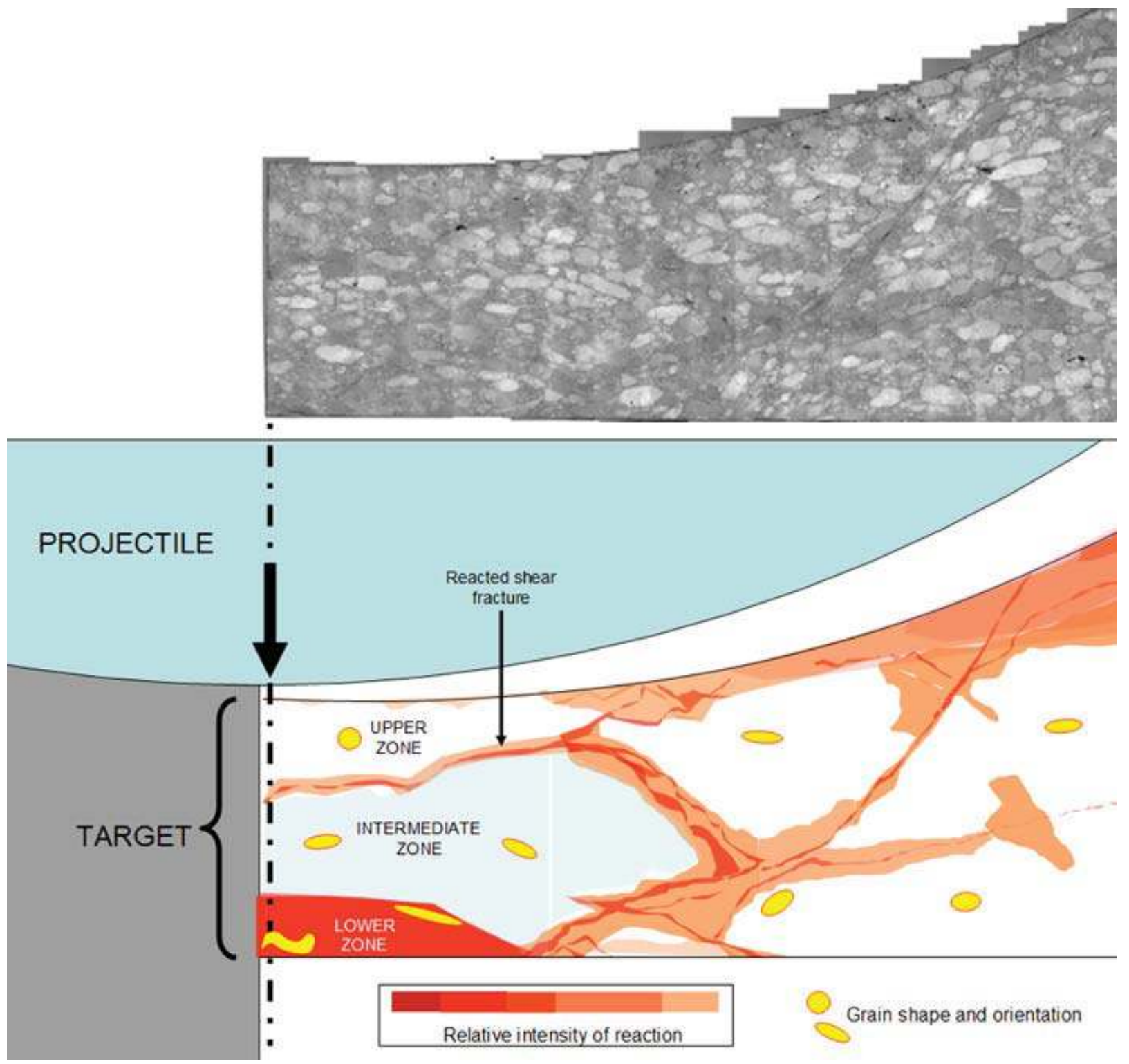

Figure 9.15. Top: polished cross-section of the central region of the recovered target seen under reflected polarized light with the optical microscope. Bottom: position of the main units and schematic representation of reaction and grain morphologies 
This central region is divided into three zones. The upper one, located immediately below the projectile, suffered little deformation, but extensive grain micro-cracking, with no strong crack orientation. It is delimited by a quasi-closed macro-crack, which experienced frictional displacement and is locally surrounded by a graded cloudy zone significant of solid phase transition, as illustrated by Figure 9.16. This upper zone is comparable to friction cones observed on compression samples, and is often observed in impact experiments as, for instance, in the case of the "punch test", where temperature measurements indicate very high temperature increase at the interface between the undeformed material in the cone and the deformed zone of the sample [HEN 98]. The pronounced macro-crack observed in our experiment is decorated with recrystallized lenses, often delimited by strong discontinuities, radially extending a few microns apart. This indicates a strong thermal gradient and quasi-punctual heat sources. Frictional sliding is, therefore, very likely to be at the origin of this morphology.

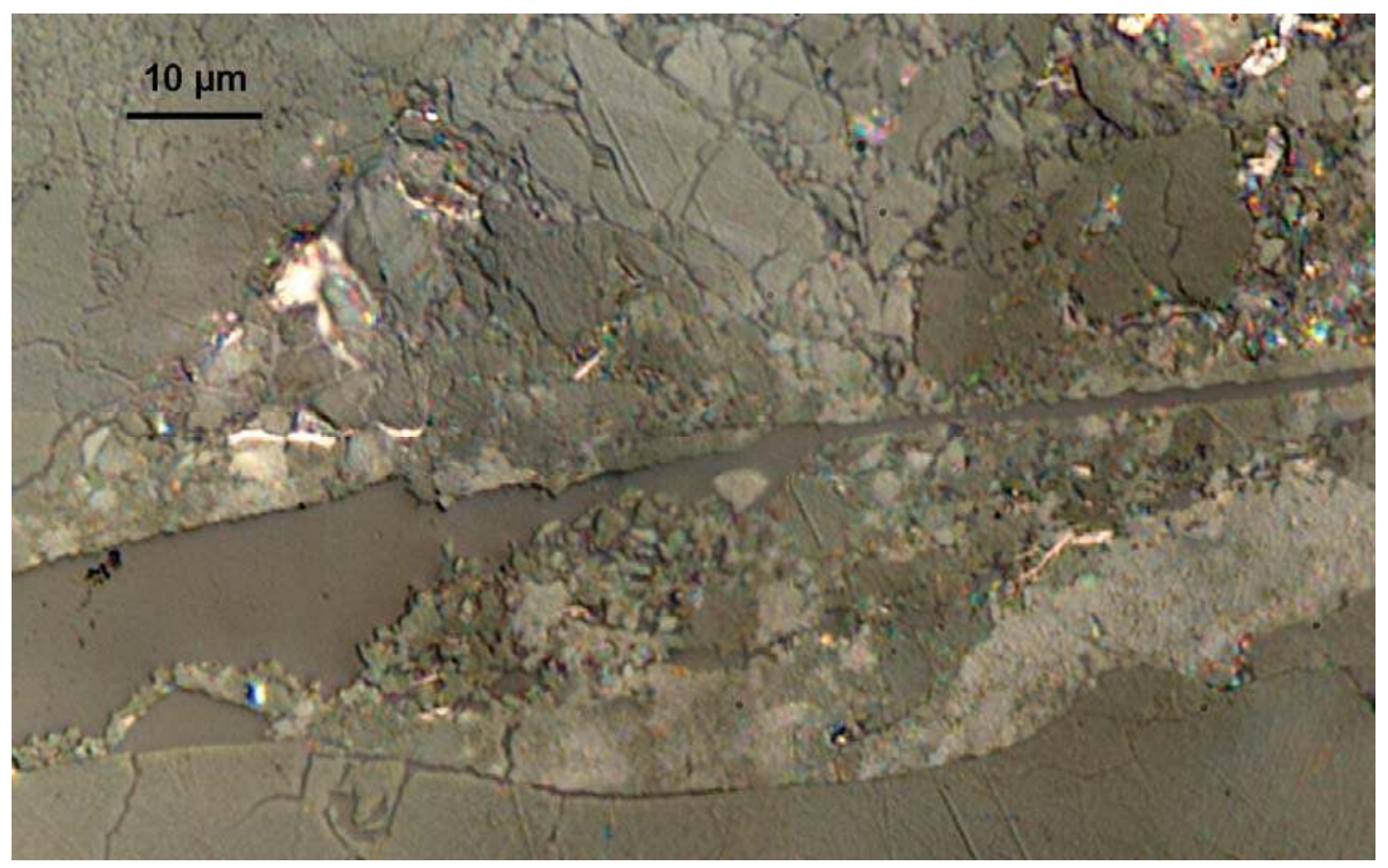

Figure 9.16. Polished cross-section of the central region of the recovered target seen under reflected polarized light with the optical microscope. Detail of the reacted shear fracture. Quasi-closed macro-crack displaying cloudy texture typical solid-solid phase transition

The intermediate zone displays dense deformation banding and extensive grain flattening, indicative of a strong radial flow that compares to that observed in the confined $800 \mathrm{MPa}$ experiment. Unlike the latter, grain micro-cracking is also very extensive in this zone. Intragranular fractures are oriented. The main orientation is pointing in the direction of the center of the projectile. Conjugate orientations are also developed. 


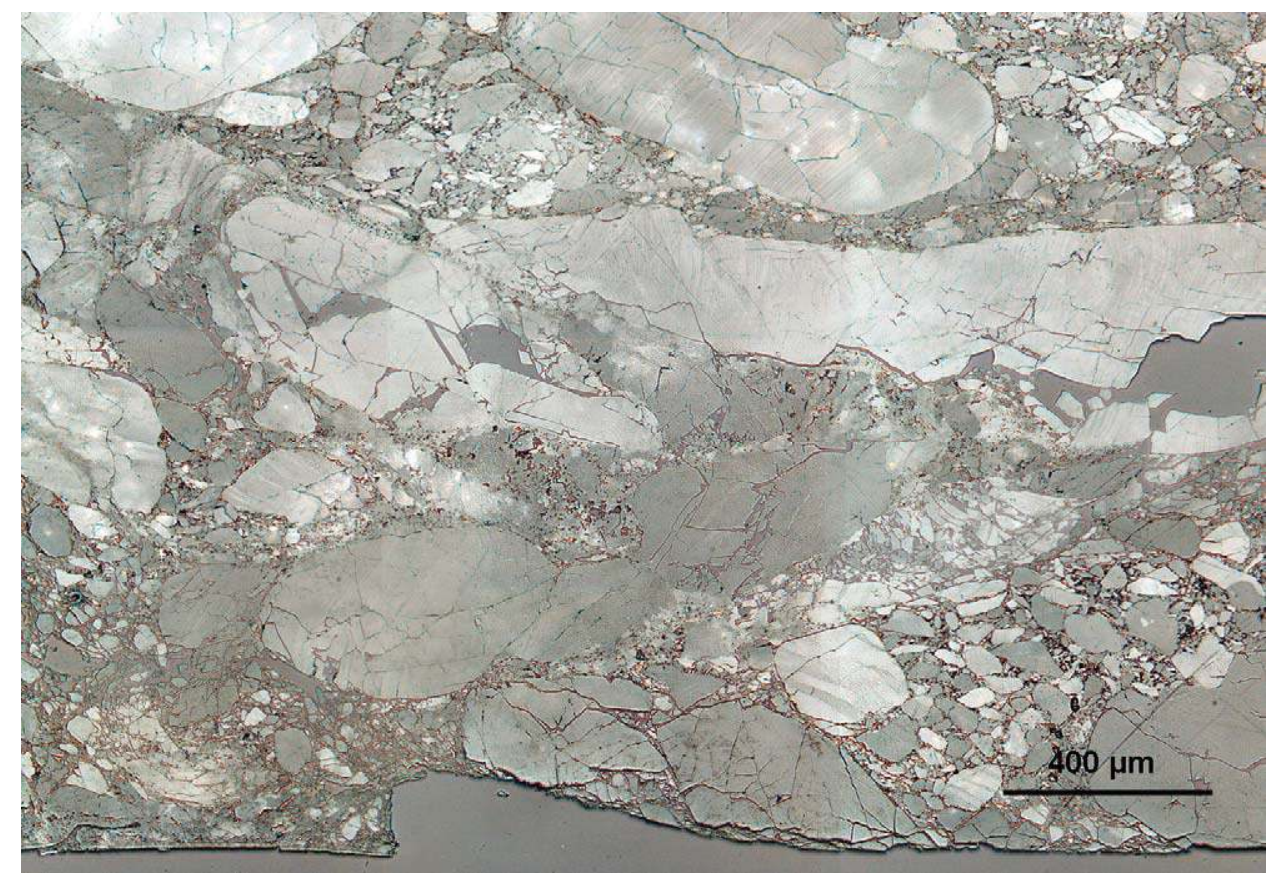

Figure 9.17. Polished cross-section of the lower part of the central region of the recovered target seen under reflected polarized light with the optical microscope. Detail of the compacted and reacted matrix (left). Note the abnormal width and wavy contour of the intragranular fracture in the grain on the right, presumably due to solid-gas reaction

The lower zone is characterized by very intense deformation banding and elongation of grains. Microcracking is less developed than in the intermediate zone. Extensive structural modifications are locally observed in the matrix which looses its initial texture. Intergranular porosity including joints with large grains is sealed, resulting in a compact texture where grains are recrystallized and phase transitions observed (Figure 9.18). Incipient solid-gas reactions are superimposed on the compact assembly resulting in a sponge-like texture illustrated in Figure 9.18.

Large and gentle bending of large grains and evidence of flows are observed in the lower part of this zone near the steel case. These features attest the viscous state of the material and suggest that local conditions were close to bulk melting in this region.

The other parts of the target also display many structural modifications. Globally, we can distinguish the surface of the crater, which is likely to have experienced extensive friction with the upper steel plate, and displays grains plasticity and comminution, as well as material gaps indicative of advanced reactive response. Elsewhere, the target shows a network of macro-cracks. Some are closed, and appear similar to the one illustrated in Figure 9.16. Others are thick, and have a quite different structure, illustrated in Figure 9.19. They contain comminuted material, and sometimes transport features, rendering them analogous to hectometric bands found in meteorite impact craters (see [LAM 09]). Elsewhere, the target shows a combination of grain plasticity and, most often, of very high granular crack density. 


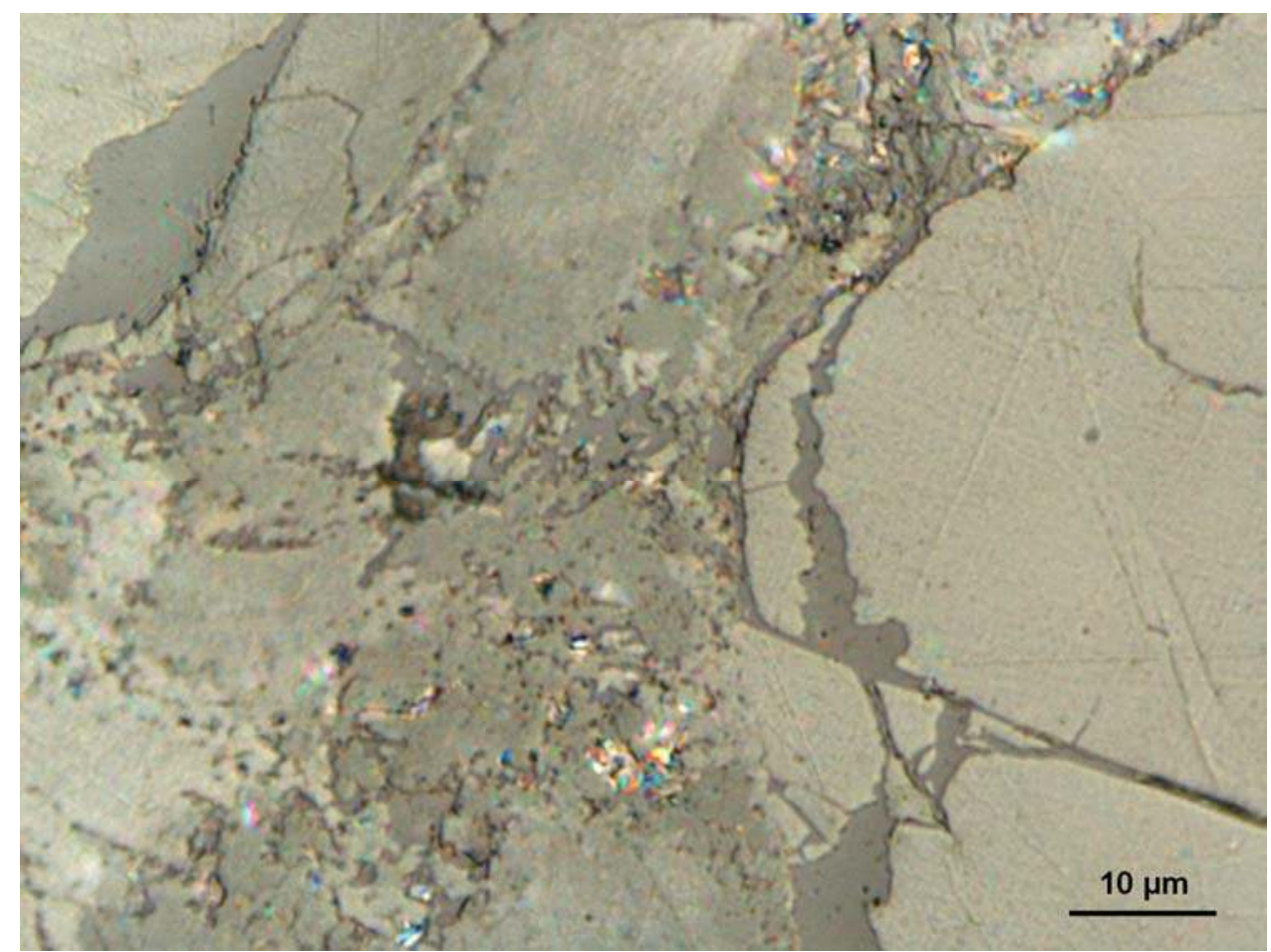

Figure 9.18. Polished cross-section of the lower part of the central region of the recovered target seen under reflected polarized light with the optical microscope. Detail of the compacted and reacted matrix with a massive cloudy texture and superimposed disseminated submicronic voids (left). On the right, note the abnormal width and weavy contour of the intragranular fracture in the grain, interpreted as solid-gas reaction

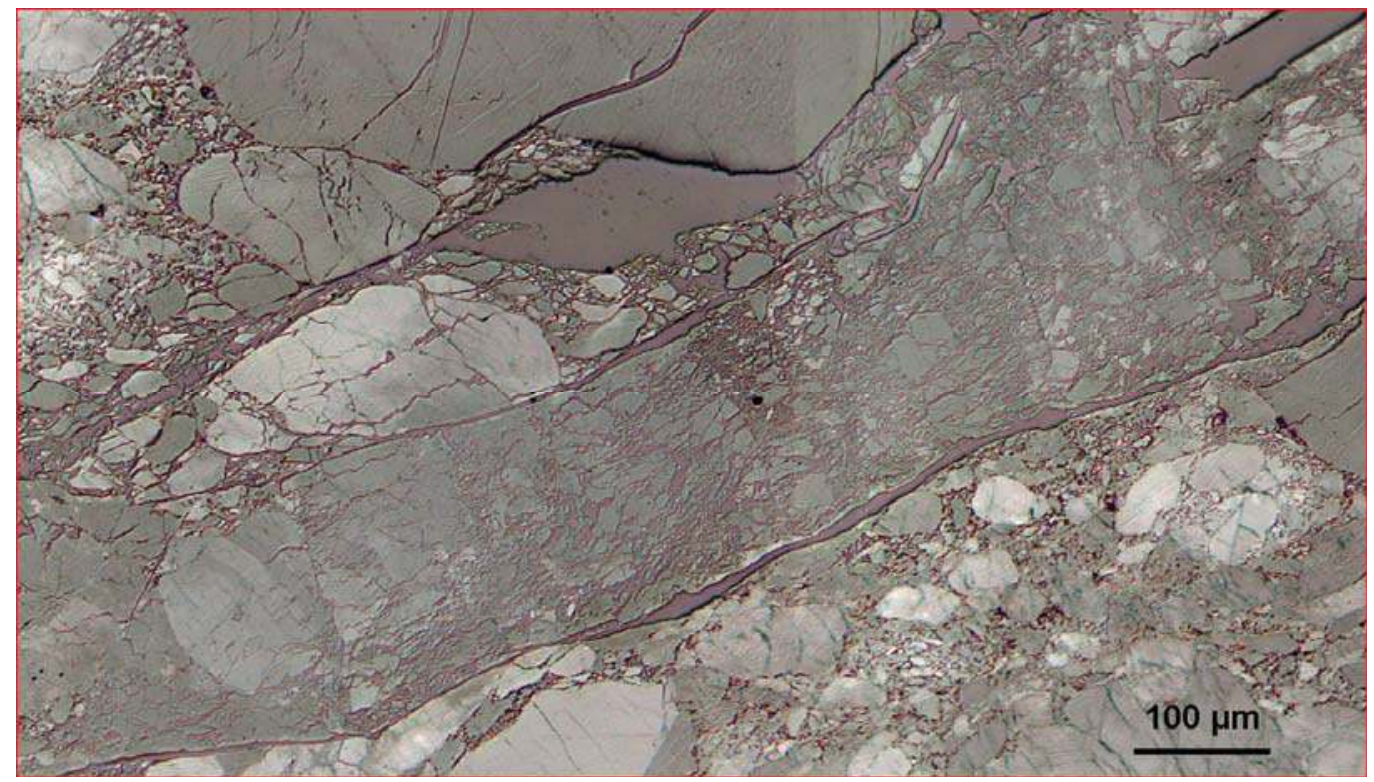

Figure 9.19. Polished cross-section of the recovered target seen under reflected polarized light with the optical microscope. Detail of a large macro-crack, displaying intense fracturing and fragmentation (comminution)

It could be thought that only the central part of the target, below the projectile, would display large structural modifications and strong reactive anomalies. This is 
not definitely the case, and many zones are as affected, especially along closed macro-cracks.

\subsection{Discussion}

\subsubsection{Mechanical effects}

The explosive studied here constitutes some intermediate or hybrid between concrete-like and propellant-like materials. In order to achieve the maximum of chemical energy amount, super-high crystal packing density is demanded. In castcured solid propellants, this is usually achieved by using broad grain size distributions, but due to processing needs, crystal packing is generally limited to ca. $80 \%$ in volume. The deformation of propellant-like materials involves quasi-rigid behavior of grains, and high accommodation capability for the matrix. To this picture, grain fragmentation under high rates of strain, and grain plasticity and glassy matrix behavior must be eventually added. In stark contrast, concrete has a somewhat comparable microstructure, but the matrix is quasi-brittle and undergoes micro-cracking during straining.

In the present case, the packing density is greater than $90 \%$, and large grain contacts occur. Like in solid propellants, the matrix is rubber like but its deformation capabilities are limited by grain contacts. Besides, HMX crystals are brittle under low confinement, and offer plastic strain capabilities in the form of deformation bands [PAL 82, RAE 02] $]^{4}$. On the other hand, the rubber-like binder and matrix are viscous and stiffen at high rates of strain.

The manufacturing process, involving high pressure isostatic pressing of bindercoated molding powder, produces a homogenous isotropic microstructure. The beginning of the process is likely to induce intra-granular micro-cracking. By generating only compressive strains, high pressure inhibits grain cleavage, thus promoting plasticity. This is fully compatible with the observations on a high pressure hydrostatically loaded sample, showing virtually no difference with pristine ones.

At low triaxiality, this material behaves in a purely viscoelastic fashion in a very limited range of strains [GRA 06, GRA 09]. For quasi-static loading, damage occurs soon, and involves simultaneously grain-matrix debonding and grain cracking. The latter appears randomly oriented; since grain contacts are involved, the grain crack distribution should depend on the initial microstructure as a first approximation.

4. HMX is rather poorly known with respect to dislocations mechanics. It seems to offer very little dislocation-induced plastic deformation capability (see [ARM 09] for a review). 
In addition, it is likely that a gross orientation of debonding cracks exists and conforms to the external load directions. Debonding is rather difficult to assess using optical microscopy, and was not thoroughly studied here.

The effect of binder viscosity in a dynamically loaded sample is striking. Virtually all grains are fragmented, and the crack orientation distribution conforms to the external load ones. Therefore, grain contacts no longer play a decisive role. As the matrix stiffens, the mechanical contrast between matrix and grains decreases strongly, as does the material heterogenity, resulting in a very homogenous orthotropic damage distribution.

At high triaxiality, micro-cracking is virtually totally inhibited, and replaced by grain plasticity. It was observed that in this case a new type of micro-cracks appears orthogonal to and inside deformation bands. It means either that the plastic strain capability of the HMX crystal is subject to saturation or that local stresses experience tension. The thin deformation bands are generally accepted to be twins, but large ones, containing sub-bands, could also be relevant to martensitic phase transformations, not identified to date. As grains can accommodate a larger part of the overall deformation, the matrix is less strained, thus explaining the little amount, if any, of debonding recorded in high pressure triaxial samples.

At medium triaxiality, a mixed behavior is observed, together with the so-called phenomenon of grain buckling. This mechanism remains poorly known, due to insufficient resolution of optical microscopy. Irreversible strains are located in relatively broad bands into which a cloudy morphology develops, perhaps due to recrystallization, and erases at least a part of the previous structure.

As a quasi-brittle (or concrete-like) material, strain softening induces strain and damage localization at low triaxiality. The process takes place progressively by crack coalescence. Medium size cracks first appear, linking trans-granular and debonding crack by matrix tearing. Such meso-cracks, that orient with respect to overall loading, then gather in more or less broad bands, whose thickness may be estimated to be comparable to large grain size (a few $100 \mu \mathrm{m}$ ). The same occurs at high rates of strain. Even pressures as low as $20 \mathrm{MPa}$ reveal strongly regularizing. Macro-cracks disappear completely at $60 \mathrm{MPa}$ confining pressure, at least to $20 \%$ deformation. This stands for unitary experiments, but some very narrow closed cracks were found in the recovered target, whose origin remains unknown at present.

In the recovered target, local strains are obviously much larger than the maximum $20 \%$ of the above mentioned laboratory experiments. The analysis of observational data is therefore subject to extrapolation. However, none of the observed microstructural contradicts this global picture. All elementary mechanisms are retrieved, sometimes strongly enhanced, allowing a few deductions. 
For example, the upper central zone shows cracked but unplastified grains. Cracks are either the effects of the (weak) shock wave generated at impact or a late effect during unloading. Lack of grain plasticity must be due to the cone crack, which accommodates almost all the strains. The lower central zones undergo massive shear under superimposed high pressure, as the internal crack density of grains remains limited. Pressure is obviously lower in other parts of the target, as indicated by (i) much less grain plasticity, (ii) much higher grain crack density, (iii) grain buckling. Within the uncertainties of the present data, one could infer pressure levels higher than ca. $200 \mathrm{MPa}$ in the central zone, lower than $100 \mathrm{MPa}$ elsewhere, and of the order of 10-60 MPa where crystal buckling is observed. The central lower zone must experience strains up to roughly $80 \%$, estimated from grain elongation in this zone.

The question of matrix behavior is more difficult to assess. Globally, the rubbery nature of the binder confers high deformability to the matrix, at least at low loading rate. Its viscous nature was indirectly deduced. Besides, no obvious consequence of a pressure-induced glass transition is recorded, such as brittleness of plastic-like behavior. Its detailed evolutions (i.e. related to its composite nature) are not precisely known, and should be further investigated. A little more insight can be obtained from non-mechanical processes that will now be discussed.

\subsubsection{Non-mechanical effects}

Let us first examine the question of the solid phase transformation. This phenomenon is presently the subject of considerable interest mainly under thermal loading (see e.g. [HEN 02, SMI 02]). This transformation is known to predate ignition under thermal loading (i.e. relatively slow heating processes), and some indications on the validity of the process under more (and even very) rapid heating are available [HEN 98, CZE 04] for HMX-based materials. The monoclinic beta phase is stable at ambient conditions, and transforms into the delta phase at approximately $150^{\circ} \mathrm{C}$. This transformation is accompanied with a $6-7 \%$ volume increase, and its kinetics is rather slow. For example, the transformation temperature increases to around $200^{\circ} \mathrm{C}$ at $10^{\circ} \mathrm{C} \cdot \mathrm{min}^{-1}$ heating rate.

The specific volume increase (about 6-7\%) explains the compact morphology of the transformed matrix. On the other hand, the HMX crystal is strongly anisotropic. Therefore, the phase transformation should be sensitive to shear stresses, but, to the authors' knowledge, this point has not been investigated yet. The transformation is nevertheless unlikely to take place in a purely mechanical fashion. The same remark stands for melting (see the interesting discussion about virtual melting in [LEV 06]). 
This implies self-heating takes place in the studied samples, and the same remark stands for any thermal process, such as melting. Self heating is the result of a competition between dissipative mechanisms and thermal conduction. Transformed or melted zones are very small (some $10 \mu \mathrm{m}$ or so). At this scale, heat conduction is very effective, indicative that heat production is not only intense (the melting temperature of beta-HMX is $280^{\circ} \mathrm{C}$ ), but also rapid. It is, therefore, likely that, even in quasi-statically loaded samples, dissipative processes responsible for nonmechanical effects are very fast. This is indirectly confirmed by the vesicular glasses observed in the recovered target which reveal both the fastness of dissipative processes and the efficiency of heat conduction.

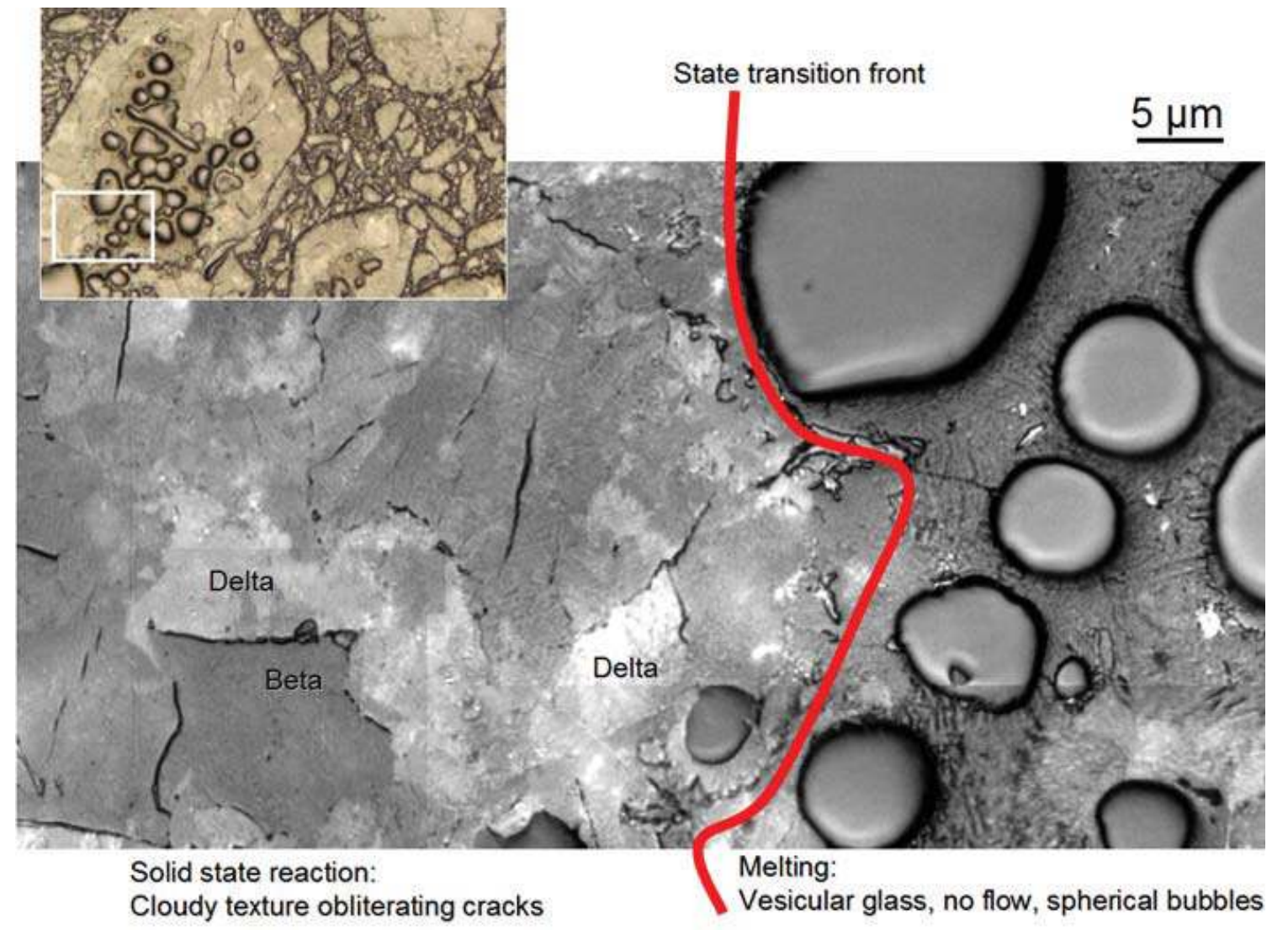

Figure 9.20. Polished cross-section of a HMX explosive recovered from a frozen combustion experiment, seen under reflected polarized light with the optical microscope. Detail of the reacted grain (see insert on the top) developing a bubble-rich flowless glass core surrounded

by an unmelted but partially transformed zone as result of solid state transformation

The efficiency of self-heating, even for low triaxiality loading conditions, for which the macroscopic dissipated power is low, raises naturally the question of hot spots mentioned in the introduction, and explains why thermal effects are often found in zones of localized deformation. The nature of hot spots is thought, after [BOW 52], to depend on the time scale available. It is generally agreed upon that pore compaction should be involved in shock to detonation transition. For lower time scales, frictional heating on small size internal surfaces (sliding cracks or boundaries) is generally considered as the best candidate [DIE 96, FIE 92], although 
alternate mechanisms have also been proposed, such as crystal plasticity [ARM 09], or crack-tip singular thermo-elastic heating [HOL 03].

Three supposedly reactive processes are mainly observed in the recovered samples, namely, melting generating vesicular glass, solid-gas reaction within grains mainly associated with intragranular cracks including worm-like cracks, and solid state re-crystallization resulting in compacted zones. A fouth one in the form of micro-cavities without resolved evidence of melting, yet different form the fist type as being diffuse instead of localized, is found in the compacted zones associated with phase transition in the recovered target.

Finding bubbles in liquid HMX is not surprising, given its well-known instability. This is typically the process at work during steady-state combustion of HMX-based energetic materials. This is illustrated in Figure 9.20 in the crosssection of a millimeter thick slab of HMX explosive recovered after a frozen combustion experiment. Melting clearly happen in the core of large grains resulting in the formation of vesicular glass while the periphery is not melted but reacted at solid state, the initial texture being partially obliterated and cracks and pores being sealed as a result of phase transformation (Figure 9.20).

No equivalent to combustion (core melting at large grain) is observed in our samples suggesting the mechanism responsible for reactive phenomena during dynamic loading is different from that involved in steady-state combustion.

Cavities along intragranular fractures in the grains, including worm-like cracks, are observed in all specimens, except high-pressure triaxial ones. In the recovered target, they are locally responsible for up to around $30 \%$ porosity in the sample. These features seem to support the hypothesis of a crack-tip thermo-elastic process mentionned above. However, neither melt nor phase change were observed in their vicinity, suggesting that the accompanying reaction is not strongly exothermic, or at least that local temperature increases remain moderate. Further work is clearly needed to constrain this hypothesis.

The diffuse submicronic voids in the compacted re-crystallized zones appear as an advanced stage of heating, beyond the phase transformation. It is unclear if the voids results from melting and represent bubbles like in the case of steady-state combustion and satisfies the generally agreed combustion scenario, beginning with phase transition, high temperature phase melting, and unstable decomposition of the liquid phase or if they relate to another mechanism. The lack of evidence of glass and large bubbles as in the case of the combustion could be a kinetic effect coupled to resolution limitation. Indeed, the size of the voids observed is at the limit of optical microscopy and thus glass may not be resolved optically. In such a case, the melted spots would be very fine, explaining why physical evidence of melt was not 
found using optical microscopy. However, the question arises to explain why the combustion extinguished and why relatively large melted spots were not found in some samples. Instead, we observe variations in the density of the tiny voids and coalescence leading eventually to sizeable pores, yet without evidence of glass, rather supporting a solid-gas hypothesis.

\subsubsection{Hot spot processes and ignition}

The term "ignition" refers to the occurrence of a macroscopic flame that will subsequently propagate and grow toward steady state combustion or explosion, depending upon the degree of confinement. In fact, the apparition of a macroscopic flame is itself the result of a series of sequential processes, namely, inert deformation, local heating, hot spot ignition, spreading and coalescence. These early steps may be referred to as the pre-ignition stage.

The questions we may address are can we tell where ignition initiates and can we tell how and when it starts and develops. In that frame, a critical question lies in determining whether ignition occurs by a distributed hot spot process or could occur in a localized fashion. In the investigated recovered target, the lower central part of the target seems indicative of a distributed hot spot process. However, this zone also contains a closed macro-crack, whose frictional sliding obviously induced phase transition, and could also be invoked in macroscopic ignition. Observations showed transformed zone to be distributed along the closed macro-crack, thus representing a surface hot spot process. More work is clearly needed to complete the present observations and to constrain the interpretations.

Regarding the mechanism issue, as seen from the above discussion, the processes which are a priori candidates for hot spot induced ignition are (i) crack-tip heating at worm like cracks, (ii) friction heating at crack and grain contacts, (iii) grain plasticity, (iv) matrix compaction, with accompanying binder viscous heating and/or grain-grain and grain-binder friction and (v) exothermic phase changes. As expressed earlier, worm-like cracks are not likely to produce efficient heating, as they induce no apparent melt or phase transition or any graded texture in their vicinity suggesting a thermal effect. Since no reaction was found in high pressure triaxial experiments, it is concluded that confinement and associated plastic deformation is not an efficient heating source under quasi-static loading to initiate reaction. It seems different under dynamic loading, as solid phase transition was observed to occur in some heavily deformed grains, often in localized plastic strain regions associated with macro faulting and shearing. Yet, no significant melting has been observed in this solid-state reacted shear zone. 
The last possibility is related to matrix deformation, often seen to undergo phase transformation. Remembering the stiffening effect of strain rate on the matrix, matrix and grains are likely to produce comparable dissipation power, both constituting good candidates for hot spot production. This picture is coherent with the probable zone of ignition of the target, near the rear steel plate, where the solidsolid phase transition invaded a significant amount of material, and where conditions for bulk melting are approached. Here too, more work is clearly needed to complete the present observations and further interpretation would be unreasonable without additional data.

\subsection{Conclusion and future work}

The material studied here offers a fairly complex behavior and associated microstructure evolutions. The methodology adopted here appears well suited to gain understanding of the material behavior, and associated microstructure evolution with respect to external loading.

However, much remains to be done. Experiments are being developed to study the effects of large deformation and combined high rates of strain and pressure, and they should provide precious data in the near future [BAI 09]. Then, analytic studies should be performed to elucidate several phenomena, among which the nature of the so-called worm-like cracks and crystal buckling. In addition, combined thermal-mechanical experiments should also be performed to study nonmechanical phenomena, and in particular the solid phase transformation and its effects on microstructure evolutions. New experiments are also being undertaken to add real-time small-scale observations during dynamic loading to post-mortem analyses.

\subsection{Acknowledgments}

The authors wish to thank MM. Patrick Rey for very careful sample preparation and polishing, and Denis Rocher for uniaxial compression experiments. They also acknowledge the financial support of the French Commissariat à l'Énergie Atomique.

\subsection{Bibliography}

[ARM 09] ARMSTRONG R. W., "Dislocation mechanics aspects of energetic material composites", Review of Advanced Material Sciences, vol. 19, pp. 13-40, 2009. 
[BAi 09] Bailly P., Delvare F., Biessy M. and Picart D., "Dynamic tests on a cohesive and frictional material. Influence of high pressure and high strain rate on compaction and shear", 9th International Conference on the Mechanical and Physical Behavior of Materials under Dynamic Loading (DYMAT 2009), Brussels, Belgium, 2009.

[BOW 52] Bowden F. P. and Yoffe A. F., Initiation and Growth of Explosions in Liquids and Solids, Cambridge University Press, Cambridge, UK, 1952.

[COF 98] COFFEy C. S. and Sharma J., "Initiation of crystalline explosives due to energy dissipated during plastic flow", 11th Internation Detonation Symposium, Snowmass, CO, USA, 1998.

[CZE 04] Czerski H., Greenaway M. W., Proud W. G. and Field J. E., "Beta-delta phase transition during dropweight impact on cyclotetramethylene-tetranitramine", Journal of Applied Physics, vol. 96, pp. 4131-4134, 2004.

[DEL 07] Delmaire-Sizes F., Belmas R., Picart D. and Trumel H., "Low velocity impact tests on an HMX-based explosive", Proc. 34th International Pyrotechnics Seminar (Association Française de Pyrotechnie ed.), Beaune, France, 2007.

[DEM 98] Demol G., LAmbert P. and TRumel H., "A study of the microstructure of pressed TATB and its evolution after several kinds of insults", 11th International Detonation Symposium, Snowmass (CO), USA, 1998.

[DIE 96] DiENES J. K., "A unified theory of flow, hot spots, and fragmentation, with an application to explosive sensitivity", DAVISON L., GRADY D. E. and SHAHINPOOR D. E., Eds., in High Pressure Shock Compression of Solids II, Springer, Berlin, 1996.

[FIE 92] Field J. E., Swallowe G. M. and Heavens S. M., "Ignition mechanisms of explosives during mechanical deformation", Proceedings of the Royal Society of London $A$, vol. 382, pp. 231-244, 1992.

[GRA 06] Gratton M., Le V. D., Caliez M. and Picart D., "Mechanical behavior of a viscoelastic-plastic granular material: experimental procedure and modelling", WSEAS Transactions on Computers, vol. 5, no. 1, pp. 149-156, 2006.

[GRA 09] Gratton M., Gontier C., Rja Fi Allah S., Bouchou A. and Picart D., "Mechanical characterization of a viscoplastic material sensitive to hydrostatic pressure", European Journal of Mechanics A/Solids, vol. 28, no. 15, pp. 935-947, 2009.

[GRU 09] Gruau C., Picart D., Belmas R., Bouton E., Delmaire-Sizes F., Sabatier J. and TRUMEL H., "Ignition of a confined high explosive under low velocity impact", International Journal of Impact Engineering, vol. 36, pp. 537-550, 2009.

[Hen 98] Henson B. F., Asay B. W., Dickson P. M., Fugard C. and Funk D. J., "Measurement of explosion time as a function of temperature for PBX 9501", 11th International Symposium on Detonation, Snowmass, CO, USA, 1998.

[HEN 02] Henson B. F., Smilowitz L., Asay B. W. and Dickson P. M., "The beta-delta transition in the energetic nitramine octahydro-1,3,5,7-tetranitro-1,3,5,7-tetrazocine: thermodynamics", Journal of Chemical Physics, vol. 117, pp. 3780-3788, 2002. 
[HEN 06] Henson B. F., Smilowitz L., Asay B. W., Sandstrom M. M. and Romero J. J., "An ignition law for PBX9501 from thermal explosion to detonation", 13th International Symposium on Detonation, Portland, OH, USA, 2006.

[HOL 99] Holmes W., Francis R. S. and FAYeR M. D., "Crack propagation induced heating in crystalline energetic materials", Journal of Chemical Physics, vol. 110, pp. 3576-3583, 1999.

[LEG 04] Le Gallic C., Belmas R. and LAMBert P., "Preheating sensitization of a TATB composition. Part two: Microstructure evolution", Propellants, Explosives and Pyrotechnics, vol. 29, pp. 339-343, 2004.

[LEV 06] Levitas V. I., Henson B. F., Smilowitz L. B. and Asay B. W., "Solid-solid phase transformation via internal stress-induced virtual melting, significantly below the melting temperature. Application to HMX energetic crystal", Journal of Physical Chemistry B, vol. 110, pp. 10105-10119, 2006.

[NAD 06] Nadot C., Dragon A., Trumel H. and Fanget A., "Damage modling framework for viscoelastic particulate composites via a scale transition approach", Journal of Theoretical and Applied Mechanics, vol. 44, no. 3, pp. 553-583, 2006.

[PAL 82] Palmer S. J. P. and Field J. E., "The deformation and fracture of $\beta$-HMX", Proceedings of the Royal Society of London A, vol. 383, pp. 399-407, 1982.

[RAE 06] RAE P. J., Hooks D. E. and LiU C., "The stress versus strain response of single $\beta$ HMX crystals in quasi-static compression", 13th International Symposium on Detonation, Norfolk, VA, USA, 2006.

[SKI 99] Skidmore C. B., Phillips D. S., IdAR D. J. and Son S. F., "Characterizing the microstructure of selected high explosives", in EuroPyro 99, Brest, France, 1999.

[SMI 02] Smilowitz L., Henson B. F., Asay B. W. and Dickson P. M., "The beta-delta transition in the energetic nitramine octahydro-1,3,5,7-tetranitro-1,3,5,7-tetrazocine: Kinetics”, Journal of Chemical Physics, vol. 117, pp. 3780-3788, 2002.

[TRU 01a] Trumel H., Dragon A., Fanget A. and Lambert P., "A constitutive model for the dynamic and high-pressure behavior of a propellant-like material: Part I. Experimental background and general structure of the model", International Journal for Numerical and Analytical Methods in Geomechanics, vol. 25, pp. 551-579, 2001.

[TRU 01b] Trumel H., Dragon A., Fanget A. and Lambert P., "A constitutive model for the dynamic and high-pressure behavior of a propellant-like material: Part II. Model development and applications", International Journal for Numerical and Analytical Methods in Geomechanics, vol. 25, pp. 581-603, 2001. 
[VIV 07] Vivier G., Hild F., Labrunie M., Lambert P. and Trumel H., "Studying and modelling a pressed HMX-based energetic material", 17th DYMAT Technical Meeting, "The High Rate Mechanical Properties of Energetic Materials, their Binders, their Simulants", Cambridge, UK, 2007.

[VIV 09] Vivier G., Trumel H. and Hild F., "On the stored and dissipated energies in heterogenous rate-independent systems: theory and simple examples", Continuum Mechancis and Thermodynamics, vol. 20, pp. 411-427, 2009. 